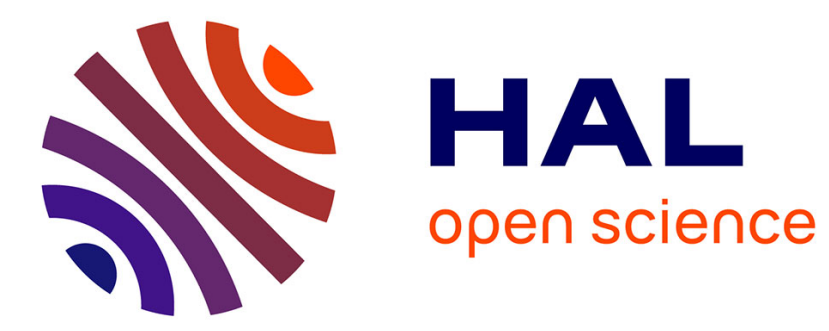

\title{
Migration measurement and modelling from poly(ethylene terephthalate) (PET) into softdrinks and fruit juices in comparison with food simulants
}

Frank Welle, Roland Franz

\section{- To cite this version:}

Frank Welle, Roland Franz. Migration measurement and modelling from poly(ethylene terephthalate) (PET) into softdrinks and fruit juices in comparison with food simulants. Food Additives and Contaminants, 2009, 25 (08), pp.1033-1046. 10.1080/02652030701837381 . hal-00577443

HAL Id: hal-00577443

https://hal.science/hal-00577443

Submitted on 17 Mar 2011

HAL is a multi-disciplinary open access archive for the deposit and dissemination of scientific research documents, whether they are published or not. The documents may come from teaching and research institutions in France or abroad, or from public or private research centers.
L'archive ouverte pluridisciplinaire HAL, est destinée au dépôt et à la diffusion de documents scientifiques de niveau recherche, publiés ou non, émanant des établissements d'enseignement et de recherche français ou étrangers, des laboratoires publics ou privés. 


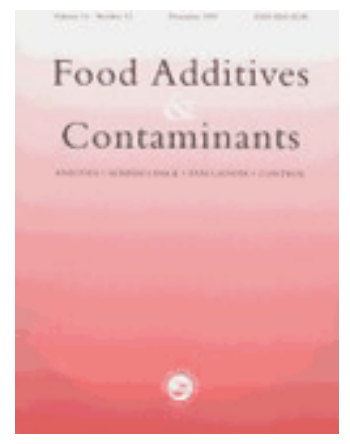

\section{Migration measurement and modelling from poly(ethylene terephthalate) (PET) into softdrinks and fruit juices in comparison with food simulants}

\begin{tabular}{|r|l|}
\hline Journal: & Food Additives and Contaminants \\
\hline Manuscript ID: & TFAC-2007-327.R2 \\
\hline Manuscript Type: & Original Research Paper \\
\hline Date Submitted by the \\
Author: & $16-$ Nov-2007 \\
\hline Complete List of Authors: & $\begin{array}{l}\text { Welle, Frank; Fraunhofer IVV } \\
\text { Franz, Roland; Fraunhofer IVV }\end{array}$ \\
\hline Methods/Techniques: & Chromatography - GC, Exposure modelling, Extraction \\
\hline Additives/Contaminants: & $\begin{array}{l}\text { Food contact materials, Migration - diffusion, Packaging - food } \\
\text { simulants, Packaging - migration modelling }\end{array}$ \\
\hline Food Types: & Beverages, Fruit juices \\
\hline &
\end{tabular}

\section{SCHOLARONE" Manuscripts}


Migration measurement and modelling from poly(ethylene terephthalate) (PET) into soft drinks and fruit juices in comparison with food simulants

Roland Franz and Frank Welle*

Fraunhofer Institute for Process Engineering and Packaging (IVV) Giggenhauser Straße 35, 85354 Freising, Germany

*Correspondence: welle@ivv.fraunhofer.de 


\section{Abstract}

Poly(ethylene terephthalate) (PET) bottles are widely used for beverages. Knowledge about the migration of organic compounds from the PET bottle wall into contact media is of interest especially when post-consumer recyclates are introduced into new PET bottles. Using migration theory the migration of a compound can be calculated if the concentration in the bottle wall is known. On the other hand, for any given specific migration limit or maximum target concentration for organic chemical compounds in the bottled foodstuffs, the maximum allowable concentrations in the polymer $\mathrm{C}_{\mathrm{P}, 0}$ can be calculated. Since a food simulant cannot exactly simulate the real migration into the foodstuff or beverages, a worse-case simulation behaviour is the intention. However, if the migration calculation should not be too over-estimative, the polymer specific kinetic parameter for migration modelling, the so-called $A_{P}$ value, should be established appropriately. One objective of the study was the kinetic determination of the specific migration behaviour of low molecular weight compounds such as solvents with relatively high diffusion rates and therefore with high migration potential from the PET bottle wall into food simulants in comparison with real beverages. For this purpose model contaminants were introduced into the bottle wall during pre-form production. The volatile compounds toluene and chlorobenzene were established at concentrations from about 20 to $30 \mathrm{mg} / \mathrm{kg}$ up to 300 to $350 \mathrm{mg} / \mathrm{kg}$. Phenyl cyclohexane was present at concentrations of $35 \mathrm{mg} / \mathrm{kg}$, $262 \mathrm{mg} / \mathrm{kg}$ and $782 \mathrm{mg} / \mathrm{kg}$, respectively. The low volatile compounds benzophenone and methyl stearate have bottle wall concentrations of about $100 \mathrm{mg} / \mathrm{kg}$ in the low spiking level up to about $1000 \mathrm{mg} / \mathrm{kg}$ in the highly spiked test bottle. From these experimental data the polymer specific parameters ( $A_{P}$ values) from mathematical migration modelling were derived. The experimental determined diffusing coefficients were determined, calculated and compared with literature data and an $A_{P}$ ' value of 1 was derived thereof for non-swelling food simulants like $3 \%$ acetic acid, $10 \%$ ethanol or iso-octane. For more swelling condition e.g. 95\% ethanol as food simulant an $A_{P}{ }^{\prime}$ value of 3.1 seems to be suitable for migration calculation. In relation to PET recycling safety aspects, maximum concentrations in the bottle wall were established 
for migrants / contaminants with different molecular weights, which correspond with a migration limit of $10 \mu \mathrm{g} / \mathrm{kg}$. From the experimental data obtained using food simulants and in comparison with beverages, the most appropriate food simulant for PET packed foods with a sufficient but not too over-estimative worse case character was found to be $50 \%$ ethanol. In addition, it can be shown that mass transport from PET is generally controlled by the very low diffusion in the polymer and, as a consequence, partitioning coefficients ( $\mathrm{K}_{\mathrm{P} / \mathrm{F}}$ values) of migrants between the polymer material and the foodstuff do not influence the migration levels significantly. An important consequence is that migration levels from PET food contact materials are largely independent from the nature of the packed food which on the other hand simplifies exposure estimations from PET.

\section{Keywords}

PET, food packaging, diffusion, migration modelling, compliance testing, exposure estimation, soft drinks, food simulants 


\section{Introduction}

Poly(ethylene terephthalate) (PET) is widely used for bottled beverage since several years. Mechanical stability, a low permeability for moisture and carbon dioxide and a high resistance to absorb food ingredients and flavours are the major advantages of PET in comparison to other packaging plastics. The high market share, which corresponds to high recovery rates, together with the high chemical inertness makes PET also the most favourite polymer for closed loop (bottle-to-bottle) recycling. Using the bottle-to-bottle recycling processes the post-consumer recycled PET is coming into direct contact with the beverages in the recyclate containing bottle. This might lead to the unwanted migration of post-consumer compounds from the bottle wall into the foodstuff. Therefore the recycling processes used for bottle-to-bottle recycling have to be very effective in the reduction of the concentrations of chemical components absorbed into the bottle wall during the first use of the material. The concentrations of post-consumer compounds in post-consumer recyclates have to be reduced to concentrations levels found in virgin PET. On the other hand, new developments in functional additives for PET, e.g. additives reducing the concentration of acetaldehyde in the bottle wall, UV absorption additives or oxygen scavenging agents, are increasing the concentration of PET untypical compounds in the bottle wall, which leads in addition to an increase of such compounds in the closed-loop recycling of PET. Knowledge about the migration of organic compounds from the PET bottle wall into contact media is therefore of interest for the use of postconsumer recyclates in new bottles applications. This may simplify in the future the usual challenge test regimen which are applied today to determine the cleaning efficiency of super-clean recycling processes (Franz 2004a) in order to establish safety for recycled PET containing food containers.

Due to their higher diffusion rates small molecules like solvents are absorbed into the bottles to a higher amount than high molecular weight compounds. Therefore the concentration of low molecular weight compounds are found to be much higher compared to larger molecules (Franz 1998, 1999, 2002, 2003, Bayer 1994, 2002, Welle 2007). On the other hand, migration of a chemical compound into the foodstuff 
is directly proportional to the concentration of the migrant in the bottle wall (Piringer $2000,2001,2007)$. Furthermore, for any given specific migration limit or maximum target concentration for organic chemical compounds in the bottled foodstuff, the maximum allowable concentrations in the polymer $\mathrm{C}_{\mathrm{P}, 0}$ can be calculated when the kinetic parameter for migration modelling, the so-called $A_{P}$ value is reliably known (Begley 2005). The $A_{P}$ value defines the basic diffusivity in a certain polymer at a given contact temperature. Such a calculation is extremely useful for the fast and economic evaluation of trace compounds in food packaging materials. Regarding PET recycling, the maximum concentration of post-consumer compounds in the foodstuff is generally accepted to be $10 \mu \mathrm{g} / \mathrm{kg}$ (FDA 1992, ILSI 1998, BgVV 2000, FDA 2006). On the other hand, in France a migration limit of $1.5 \mu \mathrm{g} / \mathrm{kg}$ is applied for post-consumer compounds in PET (AFFSA 2006).

Since PET has very low diffusion characteristics and is generally produced without huge amounts of additives there are by far not so much migration data available as for other plastics such as polyolefins. As a consequence, the migration modelling parameters which are today established and usually applied are based on fairly small data sets. Therefore, the recognised migration model (Begley 2005) for PET had to be designed such that it is sufficiently conservative. In fact, recent findings indicated (i) that for PET the model might be over-conservative and (ii) that $95 \%$ ethanol as an alternative fatty food simulant would cause significant interactions with the PET material thus leading to too exaggerated migration values compared to the fat simulant olive oil (Begley 2004). In conclusion, for PET there was not enough knowledge available concerning a satisfying answer to the question which food simulant would simulate at best foodstuffs, in particular fatty ones. Even more, the question was raised whether different food simulants would make sense at all for PET from which practically only diffusion controlled migration takes place and from which effective migration rates are therefore largely independent from the food simulant as long as a certain solubility is given (Franz 2005).

One objective of the study was the kinetic determination of the specific migration behaviour of low molecular weight compounds such as solvents with relatively high diffusion rates and therefore with high migration potential from the PET bottle wall 
into food simulants in comparison with real beverages. For this purpose model contaminants were introduced into the bottle wall during pre-form production. It was expected that in this way reliable migration data from PET would be accessible as a basis for better deriving the polymer specific parameters ( $A_{P}$ values) from mathematical migration modelling to allow prediction of migration into PET packed beverages. Furthermore, an other objective was to establish data which would allow to conclude on the most appropriate food simulant for PET packed foods. In addition, in relation to PET recycling safety aspects, maximum concentrations in the bottle wall were established for migrants / contaminants with different molecular weights, which correspond with a migration limit of $10 \mu \mathrm{g} / \mathrm{kg}$.

\section{Materials and Methods}

\section{Model contaminants for spiking PET test bottles}

The contaminants or surrogates chosen for this migration study are in accordance with US FDA (FDA 1992, FDA 2006) and in agreement with EU-relevant criteria (ILSI 1998, BgVV 2000, Franz et al 2004a, AFFSA 2006) such that they covered the whole spectrum of physical / chemical properties. The surrogates are in compliance with the four general categories of organic compounds: high volatile and polar, high volatile and non-polar, low volatile and polar as well as low volatile and non-polar. The following surrogates were used for spiking of the test bottles: Toluene (CAS No. 108-88-3), chlorobenzene (CAS No. 108-90-7), phenyl cyclohexane (CAS No. 82752-1), benzophenone (CAS No. 119-61-9) and methyl stearate (CAS No. 112-61-8).

\section{Manufacturing of spiked PET test bottles}

The neat surrogates were given to thoroughly dried virgin PET pellets. The contaminated batches were kept under nitrogen atmosphere for $38^{\circ} \mathrm{C}$ for $7 \mathrm{~d}$ with periodical agitation. The contaminated material was then used without further predrying for manufacturing of $24.5 \mathrm{~g}$ PET preforms. The preforms were shipped to a 
bottle manufacturing plant where they were blown to 0.3 I PET bottles. Subsequently the bottle wall concentrations of the surrogates in the spiked test bottles were determined.

\section{Determination of the bottle wall concentrations of the spiked PET test bottles}

The PET bottles were cut into pieces of about $0.5 \times 0.5 \mathrm{~cm} .1 .0 \mathrm{~g}$ of the PET sample

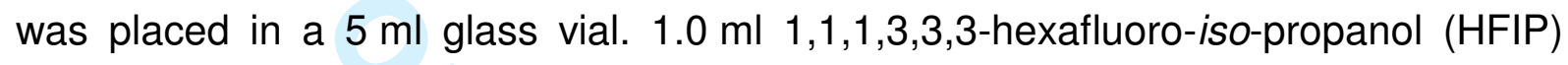
was given to the PET material and stored for $1 \mathrm{~d}$ at $60{ }^{\circ} \mathrm{C}$. The swollen polymer was extracted with $2.0 \mathrm{ml}$ iso-propanol for $1 \mathrm{~d}$ at $60^{\circ} \mathrm{C}$. The extract was decanted from the polymer and stored for overnight at $4{ }^{\circ} \mathrm{C}$. Subsequently the extracts were decanted from the precipitate and analysed by GC/FID. Gas chromatograph: HP 5890II, column: SE 10, length: $30 \mathrm{~m}$ inner diameter: $0.32 \mathrm{~mm}$, film thickness: $0.32 \mu \mathrm{m}$, temperature program: $40{ }^{\circ} \mathrm{C}(5 \mathrm{~min})$, rate $15^{\circ} \mathrm{C} \mathrm{min}{ }^{-1}, 240{ }^{\circ} \mathrm{C}(15 \mathrm{~min})$, pressure: $50 \mathrm{kPa}$ hydrogen, split: $10 \mathrm{ml} \mathrm{min}^{-1}$. Quantification was achieved by external calibration using standard solutions of different concentrations of the surrogate.

\section{Softdrinks, juices and food simulants used for the migration kinetics}

The migration of the surrogates was determined into the food simulants $3 \%$ acetic acid, $10 \%$ ethanol, $50 \%$ ethanol and $95 \%$ ethanol. In addition to the food simulants the migration of the model compounds into real beverages and juices was determined. The following beverages and juices were used for the migration tests: Orange juice (with pulp), apple juice (cloudy), apple juice (clear), vitamin ACE juice, flavoured water 1 (apple kiwi), flavoured water 2 (peach) and a soft drink (cola). The beverages were purchased in local supermarkets and filled into the spiked test bottles (volume: $300 \mathrm{ml}$, calculated food contact area $0.28 \mathrm{dm}^{2}$ ). In order to avoid microbiological contamination the beverages were spiked with sodium azide at a level of $0.01 \%$. It can be expected that this sodium azide concentration would not affect the migration behaviour of the test systems. 


\section{Specific migration testing}

For migration testing, the bottles were filled with the food simulants. Two bottles were filled for each surrogate bottle wall concentration level and food simulant / beverage. The bottles were sealed with HDPE closures with an aluminum film on the contact surface in order to prevent sorption of the surrogates into the closures. Subsequently the bottles were stored in a climate chamber at $40{ }^{\circ} \mathrm{C}$. After $3 \mathrm{~d}, 6 \mathrm{~d}, 10 \mathrm{~d}, 20 \mathrm{~d}$ and $30 \mathrm{~d}$ an aliquot of $50 \mathrm{ml}$ of the food simulant and beverages were drawn. After drawing the aliquots, the bottles were refilled with the same amount of food simulant or beverage. The inherent dilution effect was considered in the calculation of the effective concentration of the surrogates from the measured values.

\section{Determination of the model contaminants in the migrations solutions}

The concentration of the volatile and medium volatile surrogates toluene, chlorobenzene, phenyl cyclohexane in the food simulants was determined using purge and trap gas chromatography with flame ionization detection (FID). Sample preparation: a) $3 \%$ acetic acid: $5 \mathrm{ml}$ of the $3 \%$ acetic acid migration solution was neutralized with $1 \mathrm{ml}$ of $20 \%$ caustic soda $(\mathrm{NaOH})$ solution in water. b) $10 \%$ ethanol: $10 \mathrm{ml}$ of the $10 \%$ ethanol migration solution. c) $50 \%$ ethanol: $5 \mathrm{ml}$ of the $50 \%$ ethanol migration solution was diluted with $5 \mathrm{ml}$ of distilled water. d) $95 \%$ ethanol: $2 \mathrm{ml}$ of the $95 \%$ ethanol migration solution was diluted with $8 \mathrm{ml}$ of distilled water. e) real beverages (juices, cola): $1 \mathrm{ml}$ of the migration solution was diluted with $9 \mathrm{ml}$ of distilled water. f) real beverages (flavoured water): $10 \mathrm{ml}$ of the migration solution was transferred without dilution. Subsequently all solutions were analysed by purge and trap gas chromatography (FID). Method: Gas chromato $\neg$ graph: Carlo Erba 5300 Mega, column: ZB 624, length $60 \mathrm{~m}$, inner diameter $0.32 \mathrm{~mm}$, film thickness $1.8 \mu \mathrm{m}$, carrier gas: $120 \mathrm{kPa}$ helium, Temperature program: $35{ }^{\circ} \mathrm{C}(6 \mathrm{~min})$, rate $5{ }^{\circ} \mathrm{C} \mathrm{min}{ }^{-1}$, $90{ }^{\circ} \mathrm{C}$ (0 min) rate $10{ }^{\circ} \mathrm{C} \mathrm{min}^{-1}, 260{ }^{\circ} \mathrm{C}$ (15 min). Purge and trap conditions (PTA 3000): Sample temperature $40{ }^{\circ} \mathrm{C}$, purge time: $20 \mathrm{~min}$, purge flow: $20 \mathrm{ml} \mathrm{min}^{-1}$, trap temperature: $-65{ }^{\circ} \mathrm{C}$, desorption temperature: $200{ }^{\circ} \mathrm{C}$, desorption time: 7 min, water 


\section{Detection limits}

The detection limits were determined according to DIN 32645 (DIN 1994). The detection limits for the determination of the surrogates in the bottle wall and in the migration solutions are given in Table 1.

Place here Table 1

Headspace screening of the spiked test bottles for verification purposes

$1.0 \mathrm{~g}$ of the PET was weighed into a headspace vial and analysed via headspace gas chromatography (FID). Gas chromatograph: Perkin Elmer AutoSystem XL, 
column: ZB 1, length: $30 \mathrm{~m}$, inner diameter: $0.25 \mathrm{~mm}$, film thickness: $0.32 \mu \mathrm{m}$, temperature program: $50^{\circ} \mathrm{C}(4 \mathrm{~min})$, rate $20^{\circ} \mathrm{C} \mathrm{min}{ }^{-1}, 320^{\circ} \mathrm{C}(15 \mathrm{~min})$, pressure:

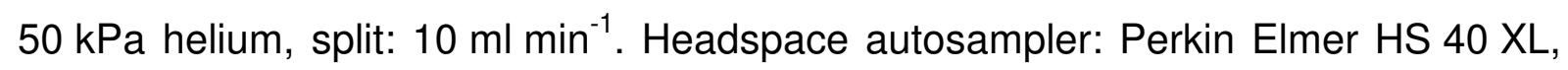
oven temperature: $200^{\circ} \mathrm{C}$, needle temperature: $210{ }^{\circ} \mathrm{C}$, transfer line: $210^{\circ} \mathrm{C}$, equilibration time: $1 \mathrm{~h}$, pressurization time: $3 \mathrm{~min}$, injection time: $0.02 \mathrm{~min}$, withdrawal time: $1 \mathrm{~min}$. The identification / characterisation was achieved by coupling the headspace gas chromatography to a mass spectrometer. Gas chromatograph: Hewlett Packard 6890, column: Optima $1 \mathrm{MS}$, length: $30 \mathrm{~m}$, inner diameter: $0.25 \mathrm{~mm}$, film thickness: $0.25 \mu \mathrm{m}$, temperature program: $50^{\circ} \mathrm{C}(4 \mathrm{~min})$, rate $20^{\circ} \mathrm{C} \min ^{-1}, 320^{\circ} \mathrm{C}$ (15 min), full scan, $\mathrm{m} / \mathrm{z}$ 40-500. Headspace autosampler: Perkin Elmer HS $40 \mathrm{XL}$, oven temperature: $200^{\circ} \mathrm{C}$, needle temperature: $210^{\circ} \mathrm{C}$, transfer line: $210^{\circ} \mathrm{C}$, equilibration time: $1 \mathrm{~h}$, pressurization time: $3 \mathrm{~min}$, injection time: $0.04 \mathrm{~min}$, withdrawal time: $1 \mathrm{~min}$. The mass spectra that were obtained were identified by comparison with spectra in the NIST spectral library.

\section{Experimental determination of diffusion coefficients}

The diffusion coefficients for the applied surrogates were calculated from the experimental migration kinetics data for the infinite case according to equation 1 (Piringer 2007).

Place here equation 1

\section{Migration modelling}

In addition to the experimental migration test, a migration model based on diffusion coefficient estimation of organic chemical substances in polymers has been used (Piringer 2000). This model has been validated within the EU project SMT-CT987513 (Piringer 2001, Begley 2005). The calculation of the migration was performed using the MIGRATEST® Lite 2001 software (Fabes GmbH, Munich, Germany). 


\section{Results}

\section{Spiking levels of test bottles}

The five model compounds were spiked into the test bottles at three concentration levels. This was achieved by introducing the model compounds on the PET pellet level before preform manufacture. After contamination of the virgin PET pellets, the spiked material was introduced directly into the preform production process. In this way a homogeneous distribution of the model compounds in the bottle wall was ensured. Application of different contamination levels allows an extrapolation of the experimental migration data to other concentration levels, due to the fact that migration of a compound into a contact media is directly linked to the concentration of the compound in the bottle wall (Piringer 2000, 2001, 2007). After the bottle manufacturing process, the concentrations of the model compounds in the bottle wall were determined by gas chromatographic analysis. The volatile compounds toluene and chlorobenzene were established at concentrations from about 20 to $30 \mathrm{mg} / \mathrm{kg}$ up to 300 to $350 \mathrm{mg} / \mathrm{kg}$. Phenyl cyclohexane was present at concentrations of $35 \mathrm{mg} / \mathrm{kg}$, $262 \mathrm{mg} / \mathrm{kg}$ and $782 \mathrm{mg} / \mathrm{kg}$, respectively. The low volatile compounds benzophenone and methyl stearate have bottle wall concentrations of about $100 \mathrm{mg} / \mathrm{kg}$ in the low spiking level up to $974 \mathrm{mg} / \mathrm{kg}$ and $1029 \mathrm{mg} / \mathrm{kg}$, respectively, in the highly spiked test bottle.

In addition to the quantitative determination by solvent extraction, the spiked PET test bottles were analysed by headspace gas chromatography for verification purposes. The applied method is generally used for screening of post-consumer PET recyclates (Franz 2004b). In the virgin PET reference sample only PET typical compounds like acetaldehyde (retention time $R_{t}=1.7 \mathrm{~min}$ ), 2-methyl-1,3-dioxolane $\left(R_{t}=2.4 \mathrm{~min}\right)$ and ethylene glycol $\left(R_{t}=2.7 \mathrm{~min}\right)$ could be determined (Figure 1). Acetaldehyde is a thermal degradation product of poly(ethylene terephthalate) whereas ethylene glycol is one of the monomers. 2-Methyl-1,3-dioxolane is the condensation product of acetaldehyde and ethylene glycol, which was generated during the preform production process in the PET melt phase. In the spiked samples 
the artificially introduced surrogates were identified by mass spectrometry as well as by comparison of the retention time of neat standard substances: toluene $\left(R_{t}=\right.$ $3.6 \mathrm{~min})$, chlorobenzene $\left(R_{t}=4.4 \mathrm{~min}\right)$, phenyl cyclohexane $\left(R_{t}=10.7 \mathrm{~min}\right)$, benzophenone $\left(R_{t}=12.8 \mathrm{~min}\right)$ and methyl stearate $\left(R_{t}=15.7 \mathrm{~min}\right)$.

place here Figure 1

Specific migration of the surrogates into softdrinks, juices and food simulants

The specific migration of the model compounds toluene, chlorobenzene and phenyl cyclohexane into the food simulants as well as the investigated beverages and juices were determined by purge and trap gas chromatography .The great advantage of this method is that the migration solutions can be directly and extremely sensitively analysed without additional sample preparation. However, high alcoholic simulants (50\% and 95\% ethanol) have to be diluted with distilled water prior to the purging the analytes. This method enables detection limits in the range of approximately $1 \mu \mathrm{g} / \mathrm{kg}$ (Table 1).

Table 2 to Table 4 summarize the specific migration results of the surrogates toluene, chlorobenzene and phenyl cyclohexane for the different applied bottle wall concentrations into the food simulants. For the highest concentration level of the surrogates in the spiked PET test bottles, the specific migration was also measured into real beverages. These results for toluene and chlorobenzene are given in Table 5 and Table 6 . The concentrations for phenyl cyclohexane was below the analytical detection limit of $1.2 \mu \mathrm{g} / \mathrm{kg}$ up to a storage time of $30 \mathrm{~d}$ at $40{ }^{\circ} \mathrm{C}$. The migration kinetics for the highest spiking levels are visualised in Figure 2 to Figure 6 for toluene and chlorobenzene as a function of the square root of time to better visualize the relationships. Since the vitamin ACE juice shows the highest migration among all investigated beverages, the migration into the ACE juice is shown for comparison reasons in the graphs for the food simulants as well.

The migration kinetics into the beverages followed in every case the expected linear behaviour between the square root of time and the concentration. For the low 
molecular weight surrogates toluene and chlorobenzene the highest migration rates were observed. The vitamin ACE juice shows the highest migration, followed by orange juice and the flavoured water samples. The migration of toluene and chlorobenzene into cola and the two apple juices was determined to be lower than for the other investigated beverages. One reason for the higher migration into ACE juice might be the pulp fraction. For example Paseiro et al (2008) found a 2.5 times higher migration of diphenylbutadiene from LDPE into orange juice if the orange juice contains pulp.

Place here Table 2

Place here Table 3

Place here Table 4

Place here Table 5

Place here Table 6

Place here Figure 2

Place here Figure 3

Place here Figure 4

Place here Figure 5

Place here Figure 6

\section{Measured values versus migration modelling}

The experimental results of this study represent valuable data which can be used to refine current migration models. These migration models which are based on the estimation of the diffusion coefficient $D_{P}$ in the polymer as the migration rate limiting step (Begley 1993, 2005, Baner 1996, Piringer 2001, 2007) are currently used for the conservative calculation of the migration of compounds from the bottle wall into liquid contact media, in particular into liquid food simulants. Starting from the known or 
(comfortably) measurable concentration of a given compound in the bottle wall, the migration can be calculated under consideration of the application conditions such as the storage time and temperature, fat or alcohol concentration of the product, contact area of the bottle and volume of the bottled drink. With the current model, the crucial parameter for modelling is the polymer specific $A_{P}$ value which characterizes the polymer typical diffusion behaviour and which can be used to comfortably calculate the diffusion coefficient $D_{P}$ of a given organic molecule in a given polymer as a function of the molecular weight of the molecule and the temperature (Equation 2)

place here Equation 2

In general, soft polymers such as low density polyethylene (LDPE) with higher diffusion constants are characterised by higher $A_{P}$ values whereas stiff chain polymers such as polyesters with lower diffusion constants have lower $A_{P}$ values. Where $A_{P}$ varies with temperature, $A_{P}$ is introduced as a temperature independent term. It should also be noted that this concept was designed statistically such that it estimates upper-bound values and therefore leads to an over-estimative migration calculation. An over-estimative model is necessary from a consumer protection and legislation point of view. Both, the parameter $\tau$ and the constant 10454, contribute to the diffusion activation energy $E_{A}\left[\mathrm{KJ} \mathrm{mol}^{-1}\right]=R(10454+\tau)$. From literature data it was concluded that $\tau=0 \mathrm{~K}$ for many polymers. When, as an example, setting $\tau=0 \mathrm{~K}$ as a first approximation for LDPE than follows $E_{A}=86.92 \mathrm{~kJ} \mathrm{~mol}^{-1}$. This is in good agreement with the mean value of $E_{A}=87 \mathrm{~kJ} \mathrm{~mol}^{-1}$ found from literature data (Mercea 2000a, 2000b). For other important groups of plastics relevant to food packaging, e.g. high-density polyethylene (HDPE) and polyethylene terephthalate (PET), a higher activation energy is generally observed. For $\tau=1577 \mathrm{~K}$ which is currently applied in the migration model in these cases, a good mean value for these matrices $E_{A}=100 \mathrm{~kJ} \mathrm{~mol}^{-1}$ is obtained. Nevertheless, it is known that in a given polymer and temperature range different migrants has different diffusion activation energies $E_{A}$ (Feigenbaum 2005, Dole 2006a, 2006b). For simplifying reasons, in migration modelling the polymer related mean values are used with the consequence that over-estimation occurs and varies depending on the real activation energy. The 
margin of overestimation is finally a function of the polymer and is generally higher in cases of lower diffusion e.g. high molecular weights migrants or non polyolefins.

Concerning migration modelling from $P E T$, currently $A_{P}^{\prime}=6$ in combination with $\tau=1577 \mathrm{~K}$ with an application temperature up to $175{ }^{\circ} \mathrm{C}$ has been established (Begley 2005) and is generally recognised for worse case migration modelling. Recent activities coordinated by the European Commission to update and refine migration models have proposed to adapt $A_{P}{ }^{\prime}=3.1(\tau=1577 \mathrm{~K})$ for temperatures below of $70{ }^{\circ} \mathrm{C}$ and $A_{P}^{\prime}=6.4(\tau=1577 \mathrm{~K})$ for temperatures above $70{ }^{\circ} \mathrm{C}$ (EU JRC 2006):

The above described migration model was applied to each of the migrants used in this study such that for three different $A_{P}$ ' values $(6,4$ and 1) migration curves were established and plotted against the measured values. This comparison of the experimental migration results and the calculated migration for the three different A ${ }_{p}$ ' values are shown exemplaric for toluene, chlorobenzene and phenyl cyclohexane in Figure 7 to Figure 9 . In all cases it gets evident that $A_{p}^{\prime}=6$ leads to a high overestimation of the real situation. $95 \%$ ethanol which from its polarity can be expected to be the most aggressive contact medium for PET (out of the ones applied in this study) shows a good correlation with $A_{p}^{\prime}=4$ for toluene and chlorobenzene until 10 days contact time. Thereafter, the experimental data show a higher slope which indicates that ethanol solvent penetrates into the PET surface quicker than the migrants in the food direction. This effect has been described in the literature by Piringer (Piringer 1990, Franz 2000) thus generating some swelling effects and accelerating the migration of the test migrants. The crossing with the linear correlation at $A_{P}{ }^{\prime}=4$ demonstrates therefore that the diffusion coefficient of the surrogate in the PET polymer is not constant and is increasing with storage time when in contact with $95 \%$ ethanol. Indeed, looking at short contact times up to 10 days the slope of the $A_{P}^{\prime}=4$ line correlates linearly with the square root of time.

Compared to the migration into the liquid foods the curve established with $A_{P}{ }^{\prime}=1$ represents in all cases an upper limit model. Since the ACE juice which is covered by $A_{P}^{\prime}=1$ was found to be the worst case food out of all applied beverages in this study, 
the $A_{P}{ }^{\prime}=1$ line can be considered to be a worse case line for soft drinks, juices and other drinks. $10 \%$ ethanol, a legally recognised food stimulant for these products is also covered by the $A_{P^{\prime}}=1$ line. The extend of coverage or with other words the margin of safety depends obviously on the nature of the substance. It should be noted here that $10 \%$ ethanol would not cover ACE juice itself and disqualifies for being a generally suitable food simulant for beverages, soft drinks and juices. Although lacking in some cases good solubility for lipophilic substances (see the phenyl cyclohexane discussion below) $50 \%$ ethanol appears to be the most suitable simulant for these and other liquid foods. Solubility aspects were the reason to amend recently European legislation and to introduce $50 \%$ ethanol, which replaces $10 \%$ ethanol as a more appropriate food simulant for milks and milk products (European Commission 2007).

Compared to toluene and chlorobenzene, the more lipophilic substance phenyl cyclohexane shows a significant lower migration behaviour. For phenyl cyclohexane the $A_{P^{\prime}}=1$ line correlates with the migration into $95 \%$ ethanol and the migration into the liquid foods and into $10 \%$ ethanol is here clearly over-estimated. The reason for that is not quite clear but it can assumed that the polarity may be one important reason: low solubility, even in $95 \%$ ethanol and much more in $10 \%$ ethanol and the liquid foods may influence migration rates down to not detectable levels. On the other hand, activation energy for diffusion in PET may be different to toluene so that further differentiation between these molecules in migration modelling may be necessary, for instance by application of a more appropriate $\tau$ value.

Place here Figure 7

Place here Figure 8

Place here Figure 9

\section{Discussion and conclusions}

Migration into liquid foods versus food simulants 
Food simulants, in principle, should simulate the migration of a specific compound into the foodstuff. However, since a food simulant cannot exactly simulate the real migration into the foodstuff or beverages, a worse case simulation behaviour is the intention. Regarding the model migrant chlorobenzene, the food simulant $10 \%$ ethanol over-estimatively simulates the migration into the beverages except the vitamin ACE juice where it underestimates. On the other hand, for the model migrant toluene, only the migration into cola drink and both apple juices were overestimatively simulated by $10 \%$ ethanol. Migration into the other beverages was underestimated by the food simulant $10 \%$ ethanol. The food simulant $3 \%$ acetic acid was found to be almost fully unsuitable as a food simulant for the investigated beverages. Only the softdrink cola was appropriately simulated by this acidic simulant. The surrogate phenyl cyclohexane shows a very low migration into the investigated beverages as well as into $10 \%$ ethanol and $3 \%$ acetic acid even at a concentration of $782 \mathrm{mg} / \mathrm{kg}$ of this surrogate in the bottle wall. Migration levels were in all cases below or at the analytical detection limit of approximately $1.2 \mathrm{Mg} \mathrm{I}^{-1}(\mathrm{ppb})$. Only after $30 \mathrm{~d}$ at $40{ }^{\circ} \mathrm{C}$ the concentration of phenyl cyclohexane in $10 \%$ ethanol was determined slightly above the detection limit to $1.6 \mu \mathrm{g} / \mathrm{kg}$. The determination of the migration of the higher molecular weight compounds benzophenone and methyl stearate with analytical detection limits in the low $\mu \mathrm{g} / \mathrm{kg}$ range was much more difficult than for the above mentioned compounds due sample preparation and analytical reasons. In fact, the achieved analytical detection limits in the migration solutions (Table 1 ) were considerably higher. The migration of methyl stearate was below the detection limits of approximately $13 \mu \mathrm{g} / \mathrm{kg}$ and $25 \mu \mathrm{g} / \mathrm{kg}$ for $3 \%$ acetic acid and $10 \%$ ethanol, respectively. Benzophenone was determined at a concentration of about $20 \mu \mathrm{g} / \mathrm{kg}$ in $10 \%$ ethanol after storage of $30 \mathrm{~d}$ at $40{ }^{\circ} \mathrm{C}$.

As already mentioned above, the food simulant $95 \%$ ethanol gave the highest migration values and with increasing diffusion coefficient which is caused by an interaction between ethanol and the polar PET matrix. This leads to a swelling effect and to an accelerated mass transfer into the simulant. Other researchers confirm this swelling effect by ethanol by their own studies, for instance when comparing the migration of benzaldehyde, limonene, anethole and benzophenone from a 1.5 I PET 
bottle into the simulants 3\% acetic acid, 95\% ethanol and a softdrink (cola) over the storage time of about one year at $40{ }^{\circ} \mathrm{C}$ as well as at $20{ }^{\circ} \mathrm{C}$ (Widen 2004). 95\% ethanol was found to be responsible for a 20-times higher migration of the applied model compounds in comparison to $3 \%$ acetic acid or cola beverage. In conclusion $95 \%$ ethanol appears to be a too strong food simulant in relation to foods, but could be used as worse case scenario if more appropriate from an analytical point of view as long as the obtained migration data are compliant with a given migration limit. $50 \%$ ethanol as food simulant gave migration values more or less in between of $95 \%$ ethanol and $10 \%$ ethanol. Taking the discussion on the comparative migration of the beverages in relation to $10 \%$ ethanol into account then one can conclude that $50 \%$ ethanol would represent the most suitable food simulant for all investigated beverages because it overestimates in all cases but not at a too exaggerated level.

\section{Migration modelling from PET}

The results show, that the migration into aqueous foodstuffs and food simulants of the low molecular weight compounds e.g. solvents like toluene and chlorobenzene are significantly higher than for high molecular compounds which was expectable from migration theory. However, the observed very low migration of phenyl cyclohexane is not satisfyingly explained by the migration model which largely overestimates the measured migration into food simulants. The reasons for that can be seen in the too low $\tau$ value of $1577 \mathrm{~K}$ generally applied for PET in the migration model which corresponds to an activation energy of approximately $100 \mathrm{~kJ} \mathrm{~mol}^{-1}$. It seems that such a low $\tau$ value is not consistent with really underlying activation energies for the diffusion in PET determined for surrogates as used here. More realistic activation energies occurring in PET have been found to range higher and up to approximately $150 \mathrm{~kJ} \mathrm{~mol}^{-1}$ which would correspond to a value for $\tau=7500 \mathrm{~K}$ (Feigenbaum. 2005; Dole 2006a). It is remarkable that the diffusion coefficient measured in these studies at $40{ }^{\circ} \mathrm{C}$ for phenyl cyclohexane was $D_{P}=8 x$ $10^{-19} \mathrm{~cm}^{2} \mathrm{~s}^{-1}$. This is extremely low and supports as a trend our migration experimental findings for phenyl cyclohexane for which we found very low migration 
under non-swelling conditions such as the food simulants $3 \%$ acetic acid and $10 \%$ ethanol as well as the foods themselves (Figure 11). For better explanation: when applying equation (1) with $A_{P}{ }^{\prime}=3.1$ or $A_{P}{ }^{\prime}=1$ and in both cases with $\tau=1577 \mathrm{~K}$ then the migration model would predict for phenyl cyclohexane $D_{P}=1.4 \times 10^{-13} \mathrm{~cm}^{2} \mathrm{~s}^{-1}$ or $D_{P}=1.7 \times 10^{-14} \mathrm{~cm}^{2} \mathrm{~s}^{-1}$, respectively. However, when using an activation energy with $126 \mathrm{~kJ} \mathrm{~mol}^{-1}(\tau=4700 \mathrm{~K})$ from the reported more realistic range then the migration model would predict $D_{P}=6.4 \times 10^{-18} \mathrm{~cm}^{2} \mathrm{~s}^{-1}$ or $D_{P}=7.9 \times 10^{-19} \mathrm{~cm}^{2} \mathrm{~s}^{-1}$, respectively. And these values coincide with the reported $D_{P}$ value as measured by Feigenbaum (2005) and Dole (2006a).

For toluene: From the experimental migration kinetics of this study the diffusion coefficient $D_{P}$ (mean values from three concentration levels) for toluene at $40{ }^{\circ} \mathrm{C}$ into $10 \%$ ethanol, $50 \%$ ethanol and $95 \%$ ethanol could be derived to be $2.0 \mathrm{x}$ $10^{-14} \mathrm{~cm}^{2} \mathrm{~s}^{-1}, 6.1 \times 10^{-13} \mathrm{~cm}^{2} \mathrm{~s}^{-1}$ and $4.1 \times 10^{-12} \mathrm{~cm}^{2} \mathrm{~s}^{-1}$, respectively. The respective $D_{P}$ values for chlorobenzene were $3.8 \times 10^{-14} \mathrm{~cm}^{2} \mathrm{~s}^{-1}, 1.1 \times 10^{-12} \mathrm{~cm}^{2} \mathrm{~s}^{-1}$ and $2.6 \mathrm{x}$ $10^{-12} \mathrm{~cm}^{2} \mathrm{~s}^{-1}$. As a trend it can be observed that with increasing ethanol concentration the $D_{P}$ value is also increasing which is the numerical description of what has been said in the above discussion on observable swelling effects caused by ethanol.

For validation purposes of our measurements, a comparison can be made with published $D_{P}$ values measured by the so-called Moisan method (Feigenbaum 2005; Dole 2006a) in PET and without the possibility of having swelling effects. These authors report $D_{P}$ values for toluene and chlorobenzene in PET at $40{ }^{\circ} \mathrm{C}$ of $3.8 \mathrm{x}$ $10^{-14} \mathrm{~cm}^{2} \mathrm{~s}^{-1}$ and $4.4 \times 10^{-14} \mathrm{~cm}^{2} \mathrm{~s}^{-1}$. These values are within the measurement precision identical with our values obtained for $10 \%$ ethanol. This simulant does not cause swelling in PET and represents therefore the matrix to be compared with. When applying migration modelling according to equation (1) then for $A_{P}$ ' $=3.1$ or $A_{P}$ ' $=1$ and in both cases with $\tau=1577 \mathrm{~K}$ follows for toluene: $D_{P}=3.8 \times 10^{-13} \mathrm{~cm}^{2} \mathrm{~s}^{-1}$ or $D_{P}=4.7 \times 10^{-14} \mathrm{~cm}^{2} \mathrm{~s}^{-1}$, respectively. For chlorobenzene $D_{P}=2.7 \times 10^{-13} \mathrm{~cm}^{2} \mathrm{~s}^{-1}$ and $D_{P}=3.4 \times 10^{-14} \mathrm{~cm}^{2} \mathrm{~s}^{-1}$, respectively, were calculated. The diffusion activation energy for toluene was reported being approximately 80 to $85 \mathrm{~kJ} \mathrm{~mol}^{-1}$ by the same authors (Feigenbaum 2005; Dole 2006a) which means that $\tau=0 \mathrm{~K}$ and that $A_{P}{ }^{\prime}=1$ is much 
more likely to be the appropriate parameters for the PET diffusion behaviour than $A_{P}$ ' $=3.1$ and $\tau=1577 \mathrm{~K}$. From Sadler et al. (Sadler 1996), for toluene $D_{P}$ values in PET were determined to be $4 \times 10^{-14} \mathrm{~cm}^{2} \mathrm{~s}^{-1}$ at $40{ }^{\circ} \mathrm{C}$ and $2 \times 10^{-15} \mathrm{~cm}^{2} \mathrm{~s}^{-1}$ at $20{ }^{\circ} \mathrm{C}$. For comparison: for toluene at $20^{\circ} \mathrm{C}$, equation (1) leads for $A_{P}{ }^{\prime}=1$ to $D_{P}=3.4 \mathrm{x}$ $10^{-15} \mathrm{~cm}^{2} \mathrm{~s}^{-1}$. Furthermore, similar $D_{P}$ values are reported by Patton (Patton 1984) for benzene by a sorption experiment into a PET film: they measured $D_{P}=6.7 \mathrm{x}$ $10^{-14} \mathrm{~cm}^{2} \mathrm{~s}^{-1}$ and $3 \times 10^{-15} \mathrm{~cm}^{2} \mathrm{~s}^{-1}$ at $40{ }^{\circ} \mathrm{C}$ and $20{ }^{\circ} \mathrm{C}$, respectively.

The results of another study (Begley 2004) can be considered and exploited to conclude on the most appropriate $A_{P}$ ' parameter. In this study the migration of Tinuvin 234 was determined. Tinvin 234 is a UV stabilizer used in PET bottles for fruit juices with a molecular weight of 447 Dalton. The migration was determined from PET into food simulants iso-octane, miglyol (fractionated coconut oil) and 95\% ethanol. The authors found that $95 \%$ ethanol caused by a factor 34 accelerated migration compared to non-swelling conditions as was the case for iso-octane and miglyol. The authors measured for Tinuvin 234 in PET at $60^{\circ} \mathrm{C}$ under non-swelling conditions $D_{P}=2.4 \times 10^{-16} \mathrm{~cm}^{2} \mathrm{~s}^{-1}$. For $A_{P}{ }^{\prime}=1$ and $\tau=1577 \mathrm{~K}$ (activation energy of $\left.100 \mathrm{~kJ} \mathrm{~mol}^{-1}\right)$ or $\tau=2750 \mathrm{~K}\left(110 \mathrm{~kJ} \mathrm{~mol}^{-1}\right)$ the model would predict $D_{P}=8.0 \mathrm{x}$ $10^{-15} \mathrm{~cm}^{2} \mathrm{~s}^{-1}$ or $D_{P}=2.4 \times 10^{-16} \mathrm{~cm}^{2} \mathrm{~s}^{-1}$, respectively. The latter corresponds exactly to the experimental data. At $40{ }^{\circ} \mathrm{C}$, Begley reports a measured $D_{P}=1 \times 10^{-18} \mathrm{~cm}^{2} \mathrm{~s}^{-1}$. Again for $A_{P^{\prime}}=1$ and $\tau=1577 \mathrm{~K}\left(100 \mathrm{~kJ} \mathrm{~mol}^{-1}\right)$ or $\tau=2750 \mathrm{~K}\left(110 \mathrm{~kJ} \mathrm{~mol}^{-1}\right)$ or $\tau=$ $3670 \mathrm{~K}\left(117 \mathrm{~kJ} \mathrm{~mol}^{-1}\right)$ the model would predict $D_{\mathrm{P}}=8.0 \times 10^{-16} \mathrm{~cm}^{2} \mathrm{~s}^{-1}$ or $\mathrm{D}^{\prime}=1.9 \mathrm{x}$ $10^{-17} \mathrm{~cm}^{2} \mathrm{~s}^{-1}$ or exactly $D_{\mathrm{P}}=1.0 \times 10^{-18} \mathrm{~cm}^{2} \mathrm{~s}^{-1}$. These data, also support, that the appropriate parameter for the basic diffusivity of PET is more $A_{P}{ }^{\prime}=1$ than $A_{P}{ }^{\prime}=3.1$ and that the correct calculation of $D_{P}$ requires implementation of good data for the activation energy.

An important conclusion from the side of the kinetical contribution to migration is that migration under non-swelling conditions such as PET in contact with miglyol, isooctane and $10 \%$ ethanol can be homogeneously described by a common $A_{p}$ ' value which is rather 1 than $3.1 .50 \%$ ethanol is already borderline and $95 \%$ ethanol would need consideration of a change in the $A_{P}$ ' value over time. On the other hand, 
regarding the thermodynamic contribution to migration the solubility of an organic migrant is higher in high ethanolic solutions which could influence the partition coefficient of the surrogates between the PET matrix and the food simulant, $\mathrm{K}_{\mathrm{P} / \mathrm{F}}=$ $\mathrm{C}_{\mathrm{P}, \infty} / \mathrm{C}_{\mathrm{F}, \infty}$. This partition coefficient, understood as the ratio of the migrant's concentration in polymer $(P)$ at equilibrium to the equilibrium concentration in the food stimulant $(\mathrm{F})$ is, according to the above mentioned migration model (Begley 2005, Piringer 2007), set to $K_{P / F}=1$ for high solubility and $K_{P / F}=1000$ for low solubility of a migrant in the food stimulant (assuming high or good solubility in the polymer). When, however, using the migration model it can be shown, that the partition coefficient plays a minor role with regard to the migration levels from PET (Figure 10). The reason for that is the low diffusivity characteristic of PET. As a consequence in practically in all migration cases it can be stated: (i) the mass transport from PET is controlled by the very low diffusion in the polymer and (ii) partitioning, at least for $\mathrm{K}_{\mathrm{P} / \mathrm{F}}$ values up to 1000 , does not influence the migration levels in the very early, kinetically controlled phase of migration. Increasing storage time up to $30 \mathrm{~d}$ reduces the bottle wall concentration corresponding to the $10 \mu \mathrm{g} / \mathrm{kg}$ threshold limit by a factor of approximately 1.7 in the case of good solubility $(K=1)$. For $K=1000$ the bottle wall concentration was reduced by a factor of 1.2 (low molecular weight compounds) and 1.7 (high molecular weight compounds), respectively. In the latter case, the partition coefficient has a slight influence for low molecular weight compounds.

The minor influence of the partition coefficient has important implications regarding PET as well as PET recyclates as a food contact material. Due to the fact, that most of the PET recyclates are used for softdrink bottles, water soluble surrogates to be used for challenge tests were always discussed. Migration modelling, and the results of this study show that surrogates with high water solubility are in fact not needed. Currently used surrogates (Franz 2004a and 2004b) such as the test migrants of this study are very suitable and furthermore it gets evident from this study that the discussion on appropriate surrogates should focus on surrogates with low molecular weights which are indeed the most critical ones and the best target analytes when it comes to validated challenge test and analytical determination procedures. 
Place here Figure 10

Realistic migration from PET into foods for exposure estimation

Due to the inherent low diffusivity of PET material and the consequential implications regarding partitioning effects (as discussed above) PET as a food contact material offers a possibility to model migration generally such that the estimate is valid for nearly any type food where non-swelling contact conditions occur. Of course and as usual, there are exemptions from the general rule, for instance, when spirituous beverages such as a brandy or whiskey are packed. These would need then to be treated separately because of the interaction with ethanol. But for the overwhelming food types which could be packed in PET one can draw advantage of the fact that migration from PET is diffusion controlled and not significantly influenced by the partition coefficient as shown in Figure 10. This conclusion has already been addressed recently (Franz 2005) in an overview article on the "Foodmigrosure" project (EU contract QLK1-CT2002-2390, www.foodmigrosure.org). The conclusion of this project was: together with information on food consumption and packaging usage general migration modelling would allow an easy and quick access to exposure estimates. Figure 11 provides a master curve which allows migration estimation in two ways: using $A_{P}{ }^{\prime}=3.1$ as a sufficient degree of overestimation is achieved so that this curve can be used for food law compliance evaluation where migration estimation needs urgently to be over-estimative. Using $A_{P}^{\prime}=1$ a more realistic migration estimation is achieved in particular when $\tau$ values can be defined or assumed according to the respective activation energy. In both cases $\tau=1577 \mathrm{~K}$ is assumed and $K_{P / F}=1$ for high solubility in the food which is the worst case. Again, these curves would indicate migration into any type of food regardless to its fatty or aqueous character. For high alcoholic contents from $50 \%$ to $90 \%$ up these curves are not valid but could be established easily using correspondingly higher $A_{p}$ ' values, which are over-estimatively $A_{p}{ }^{\prime}=6$ or more realistically $A_{p}{ }^{\prime}=4$. The curves in Figure 11 have been established for a $C_{P, 0}$ value of $100 \mathrm{mg} / \mathrm{kg}$ in PET material. It should be noted that migration is directly proportional to $C_{P, 0}$ which allows an easy estimate for 
other $\mathrm{C}_{\mathrm{P}, 0}$ values. Our experimental data demonstrates this concentration effect. The migration data for $10 \%$ ethanol for toluene in Table 2 and for chlorobenzene (Table 3) show migration increases with initial concentration in the polymer.

From the results and discussions of this paper, finally, one important conclusion can be drawn concerning the safety of recycled PET plastics: only relatively small molecules up to approximately 250 to 300 Dalton with sufficient volatility are relevant for the discussion and consideration in challenge tests. The migration potential of higher molecular weight compounds can be almost neglected even if the concentrations of these compounds have been (artificially) established for the purpose of the challenge test in the range of several hundred up to $1000 \mathrm{mg} / \mathrm{kg}$ in the bottle wall.

Place here Figure 11

\section{Acknowledgement}

The work was financially supported by the German BMBF Contract No. 330495 as well as the by the industrial platform of Colormatrix (Manchester, UK), Emig (Waibstadt, Germany), Genossenschaft Deutscher Brunnen (Bonn, Germany), Krones (Neutraubling, Germany), Nestlé Waters (Vittel, France), OHL (Limburg, Germany) and Petcycle (Bad Neuenahr, Germany). The spiked bottles were provided by PTI (Holland OH, USA). Special thanks are due to Frank Schloss (PTI), Silvia Demiani, Johann Ewender, Anita Gruner, Alexandra Mauer and Sonja Smolic (Fraunhofer IVV) for experimental contributions and fruitful discussions. 


\section{References}

AFFSA. 2006. Opinion of the French Food Safety Agency (Afssa) on the assessment of health risks associated with the use of materials made from recycled poly(ethylene terephthalate) intended for or placed in contact with foodstuffs and drinking water. Mandate no 2001-SA-0315, 27. November.

Baner L, Brandsch J, Franz R, Piringer OG. 1996. The application of a predictive migration model for evaluation the compliance of plastic materials with European food regulations. Food Additives and Contaminants 13:587-601.

Bayer FL, Myers DV, Gage MJ, 1994. Consideration of poly(ethylene terephthalate) recycling for food use. Congress procedures: 208th American Chemical Society National Meeting. Washington DC. August 25, 152-160.

Bayer FL. 2002. Polyethylene terephthalate recycling for food-contact applications: testing, safety and technologies: a global perspective. Food Additives and Contaminants 19(supplement):111-134.

Begley TH, Hollifield HC. 1993. Recycled polymers in food packaging: migration considerations. Food Technology 109-112.

Begley TH, McNeal TP, Biles JE, Paquette E. 2002. Evaluating the potential for recycling all PET bottles into new food packaging. Food Additives and Contaminants 19: Supplement, 135-143.

Begley TH, Biles JE, Cunningham C, Piringer O. 2004. Migration of a UV stabilizer from polyethylene terephthalate (PET) into food simulants. Food Additives and Contaminants 21:1007-1014.

Begley T, Castle L, Feigenbaum A, Franz R, Hinrichs K, Lickly T, Mercea P, Milana M, O'Brien A, Rebre S, Rijk R, Piringer O. 2005. Evaluation of migration models that might be used in support of regulations for food-contact plastics. Food Additives and Contaminants 22:73-90. 
BgVV 2000. Use of mechanical recycled plastic made from polyethylene terephthalate (PET) for the manufacture of articles coming in contact with food. Berlin: Bundesinstitut für gesundheitlichen Verbraucherschutz und Veterninärmedizin.

DIN 1994. DIN 32645:1994-05: Chemical analysis; decision limit; detection limit and determination limit; estimation in case of repeatability; terms, methods, evaluation.

Dole P, Feigenbaum A, De La Cruz Garcia C, Pastorelli S, Paseiro P, Hankemeier T, Voulzatis Y, Aucejo S, Saillaed P, Papaspyrides CD. 2006a. Typical diffusion behaviour in packaging polymers - Application to functional barriers. Food Additives and Contaminants 23:202-211.

Dole P, Voulzatis Y, Vitrac O, Reynier A, Hankemeier T, Aujeco S, Feigenbaum A. 2006b. Modelling of migration from multi-layers and functional barriers: estimation of parameters. Food Additives and Contaminants 23:1038-1052.

European Commission JRC (Joint Research Centre, Ispra, Italy). 2006. JRC task force on migration modelling: meeting on 4/5 July 2006 in Paris.

European Commission. 2007. Commission Directive 2007/19/EC amending Directive 2002/72/EC and Council Directive 85/572/EEC. Official Journal of the European Union L91/17 - 36.

FDA 1992. Points to consider for the use of recycled plastics in food packaging: Chemistry considerations. HFF-410. Washington, DC: US Food and Drug Administration, Center for Food Safety and Applied Nutrition.

FDA 2006, Guidance for industry: Use of recycled plastics in food packaging: Chemistry considerations. HFS-275, Washington, DC: US Food and Drug Administration, Center for Food Safety and Applied Nutrition.

Franz R, Huber M, Welle F. 1998. Recycling of post-consumer poly(ethylene terephthalate) for direct food contact application - A feasibility study using a simplified challenge test. Deutsche Lebensmittel-Rundschau 94:303-308. 
Franz R, Welle F. 1999. Post-consumer poly(ethylene terephthalate) for direct food contact applications - Final proof of food law compliance. Deutsche LebensmittelRundschau 95:424-427.

Franz R. 2000. Migration of plastic constituents. In: Piringer OG, Baner AL, editors. Plastic Packaging Materials for Food - Barrier function, mass transport, quality assurance and legislation. Weinheim Wiley-VCH, pp 287-357

Franz R, Welle F. 2002. Post-consumer poly(ethylene terephthalate) for direct food contact application - Challenge-test of an inline recycling process. Food Additives and Contaminants 19:502-511.

Franz R, Welle F. 2003. Recycling packaging materials. In: Ahvenainen R, editor. Novel food packaging techniques. Cambridge Woodhead, pp 497-518.

Franz R, Bayer F, Welle F. 2004a. Guidance and criteria for safe recycling of post consumer polyethylene terephthalate (PET) into new food packaging applications. Report No. 21155. Luxembourg: Office for Official Publications of the European Communities.

Franz R, Mauer A, Welle F. 2004b. European survey on post-consumer poly(ethylene terephthalate) materials to determine contamination levels and maximum consumer exposure from food packages made from recycled PET. Food Additives and Contaminants 21:265-286.

Franz R. 2005. Migration modelling from food-contact plastics into foodstuffs as a new tool for consumer exposure estimation. Food Additives and Contaminants 22:920-937.

Feigenbaum A, Dole P, Aucejo S, Dainelli D, De La Cruz Garcia C, Hankemeier T, N'Gono Y, Papasyrides CD, Paseiro P, Pastorelli S, Pavlidou S, Pennarun PY, Saillaed P, Vidal L, Vitrac O, Voulzatis Y. 2005. Functional barriers: Properties and evaluation. Food Additives and Contaminants 22:956-967. 
ILSI 1998. Recycling of plastics for food contact use. Guidelines prepared under the responsibility of the International Life Sciences Institute (ILSI) European Packaging Material Task Force. Brussels: ILSI.

Mercea P. 2000a. Models for diffusion in polymers. In: Piringer OG, Baner AL, editors. Plastic Packaging Materials for Food - Barrier function, mass transport, quality assurance and legislation. Weinheim Wiley-VCH, pp 125-157

Mercea P. 2000b. Diffusion data for LDPE, HDPE and PP. In: Piringer OG, Baner AL, editors. Plastic Packaging Materials for Food - Barrier function, mass transport, quality assurance and legislation. Weinheim Wiley-VCH, Appendix I.

Patton CJ, Felder RM, Koros WJ. 1984. Sorption and transport of benzene in poly(ethylene terephthalate). Journal of Applied Polymer Science 29:1095-1110.

Piringer O. 1990. Ethanol und Ethanol/Wasser-Gemische als Prüflebensmittel für die Migration aus Kunststoffen. Deutsche Lebensmittel-Rundschau. 86: 35-39.

Piringer OG, Baner AL. 2000. Plastic packaging materials for food - Barrier function, mass transport, quality assurance and legislation. Weinheim Wiley-VCH

Piringer O, Hinrichs K. 2001. Evaluation of migration models. Final Report of the EUproject contract SMT-CT98-7513, Brussels.

Piringer O. 2007. Mathematical modelling of chemical migration from food contact materials. In: Barnes KA, Sinclair R, Watson $\mathrm{DH}$, editors. Chemical migration and food contact materials. Cambridge Woodhead, pp 180-202.

Sadler G, Pierce D, Lawson A, Suvannunt D, Senthil V. 1996. Evaluating organic compound migration in poly(ethylene terephthalate): A simple test with implications for polymer recycling. Food Additives and Contaminants 13:979-999.

Sanches-Silva A, Cruz Freire JM, Franz R, Paseiro-Losada P. 2008. Timetemperature study of the kinetics of migration of diphenylbutadiene from polyethylene films into aqueous foodstuffs. Food Research International in press 
Welle F, Franz R. 2007. Recycled plastics and chemical migration into food. In: Barnes KA, Sinclair R, Watson DH, editors. Chemical migration and food contact materials. Cambridge Woodhead, pp 205-227.

Widen H, Leufven A, Nielsen T. 2004. Migration of model contaminants from PET bottles: influence of temperature, food simulant and functional barrier. Food Additives and Contaminants 21:993-1006. 
Table 1: Detection limits of the surrogates in the PET bottle wall and migration solutions according to DIN 32645 (DIN 1994)

\begin{tabular}{|c|c|c|c|c|c|c|}
\hline \multirow[t]{2}{*}{ Surrogate } & \multirow{2}{*}{$\begin{array}{l}\text { PET material } \\
{[\mathrm{mg} / \mathrm{kg}]}\end{array}$} & \multicolumn{5}{|c|}{ Migration solutions $[\mu \mathrm{g} / \mathrm{kg}]$} \\
\hline & & $\begin{array}{l}\text { juices, soft } \\
\text { drinks }\end{array}$ & $\begin{array}{l}3 \% \text { acetic } \\
\text { acid }\end{array}$ & | $10 \%$ ethanol & $50 \%$ ethanol & 95\% ethanol \\
\hline Toluene & 0.24 & 0.5 & 1.0 & 0.4 & 0.4 & 0.4 \\
\hline Chlorobenzene & 0.08 & 0.7 & 0.7 & 0.3 & 0.3 & 0.3 \\
\hline Phenyl cyclohexane & 0.06 & 1.2 & 1.1 & 0.9 & 0.9 & 0.9 \\
\hline Benzophenone & 0.09 & $\begin{array}{l}\text { not } \\
\text { determined }\end{array}$ & 8.8 & 8.8 & $\begin{array}{l}\text { not } \\
\text { determined }\end{array}$ & $\begin{array}{l}\text { not } \\
\text { determined }\end{array}$ \\
\hline Methyl stearate & 0.23 & 13.0 & 13.0 & 25.4 & 25.4 & 25.4 \\
\hline
\end{tabular}


Table 2: Migration kinetics of toluene from spiked PET bottle into food simulants at $40{ }^{\circ} \mathrm{C}$

\begin{tabular}{|c|c|c|c|c|c|c|c|c|c|c|c|c|}
\hline & \multicolumn{12}{|c|}{ Concentration in food simulant $[\mu \mathrm{g} / \mathrm{kg}]$} \\
\hline & \multicolumn{12}{|c|}{ Bottle wall concentration [mg/kg] } \\
\hline & \multicolumn{4}{|c|}{$17.6 \pm 0.6$} & \multicolumn{4}{|c|}{$70.6 \pm 0.6$} & \multicolumn{4}{|c|}{$297.5 \pm 1.2$} \\
\hline $\begin{array}{l}\text { time } \\
{[d]}\end{array}$ & $\begin{array}{l}3 \% \\
\text { acetic } \\
\text { acid }\end{array}$ & $\begin{array}{l}10 \% \\
\text { ethanol }\end{array}$ & $\begin{array}{l}50 \% \\
\text { ethanol }\end{array}$ & $\begin{array}{l}95 \% \\
\text { ethanol }\end{array}$ & $\begin{array}{l}3 \% \\
\text { acetic } \\
\text { acid }\end{array}$ & $\begin{array}{l}10 \% \\
\text { ethanol }\end{array}$ & $\begin{array}{l}50 \% \\
\text { ethanol }\end{array}$ & $\begin{array}{l}95 \% \\
\text { ethanol }\end{array}$ & $\begin{array}{l}3 \% \\
\text { acetic } \\
\text { acid }\end{array}$ & $\begin{array}{l}10 \% \\
\text { ethanol }\end{array}$ & $\begin{array}{l}50 \% \\
\text { ethanol }\end{array}$ & $\begin{array}{l}95 \% \\
\text { ethanol }\end{array}$ \\
\hline 3 & 1.1 & 1.3 & 2.6 & 30.4 & 3.8 & 6.2 & 21.2 & 53.3 & 14.5 & 24.7 & 82.2 & 169.7 \\
\hline 6 & 1.4 & 1.9 & 8.4 & 41.9 & 5.0 & 7.9 & 35.9 & 133.5 & 22.0 & 38.6 & 146.5 & 242.8 \\
\hline 10 & 1.4 & 2.3 & 11.5 & 61.1 & 2.3 & 8.6 & 49.8 & 122.3 & 14.5 & 43.4 & 205.5 & 385.9 \\
\hline 20 & n.d. & 2.3 & 17.9 & 53.0 & n.d. & 15.7 & 87.1 & 189.5 & n.d. & 63.0 & 323.4 & 583.1 \\
\hline 30 & n.d. & 4.4 & 25.1 & 80.2 & n.d. & 27.8 & 123.1 & 250.7 & n.d. & 98.5 & 437.7 & 923.3 \\
\hline
\end{tabular}

n.d. not determined 
Table 3: Migration kinetics of chlorobenzene from spiked PET bottle into food simulants at $40{ }^{\circ} \mathrm{C}$

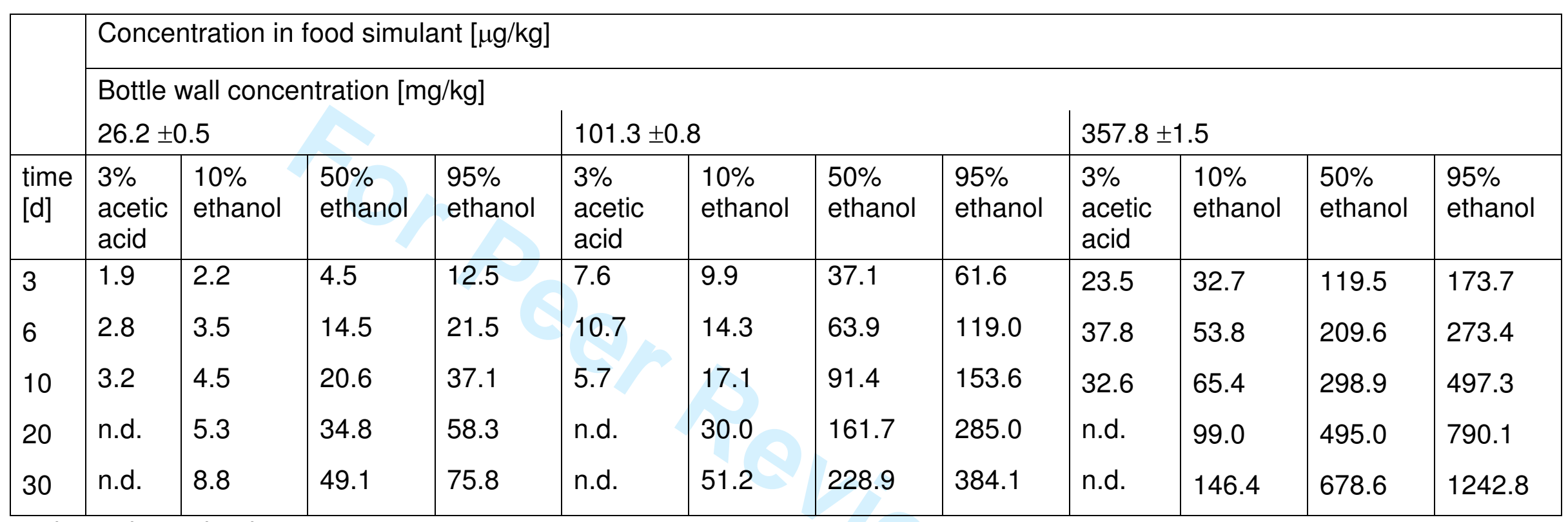

n.d. not determined 
Table 4: Migration kinetics of phenyl cyclohexane from spiked PET bottle into food simulants at $40{ }^{\circ} \mathrm{C}$

\begin{tabular}{|c|c|c|c|c|c|c|c|c|c|c|c|c|}
\hline & \multicolumn{12}{|c|}{ Concentration in food simulant $[\mu \mathrm{g} / \mathrm{kg}]$} \\
\hline & \multicolumn{12}{|c|}{ Bottle wall concentration [mg/kg] } \\
\hline & \multicolumn{4}{|c|}{$35.3 \pm 1.0$} & \multicolumn{4}{|c|}{$261.7 \pm 1.7$} & \multicolumn{4}{|c|}{$782.3 \pm 1.4$} \\
\hline $\begin{array}{l}\text { time } \\
{[d]}\end{array}$ & $\begin{array}{l}3 \% \\
\text { acetic } \\
\text { acid }\end{array}$ & $\begin{array}{l}10 \% \\
\text { ethanol }\end{array}$ & $\begin{array}{l}50 \% \\
\text { ethanol }\end{array}$ & $\begin{array}{l}95 \% \\
\text { ethanol }\end{array}$ & $\begin{array}{l}3 \% \\
\text { acetic } \\
\text { acid }\end{array}$ & $\begin{array}{l}10 \% \\
\text { ethanol }\end{array}$ & $\begin{array}{l}50 \% \\
\text { ethanol }\end{array}$ & $\begin{array}{l}95 \% \\
\text { ethanol }\end{array}$ & $\begin{array}{l}3 \% \\
\text { acetic } \\
\text { acid }\end{array}$ & $\begin{array}{l}10 \% \\
\text { ethanol }\end{array}$ & $\begin{array}{l}50 \% \\
\text { ethanol }\end{array}$ & $\begin{array}{l}95 \% \\
\text { ethanol }\end{array}$ \\
\hline 3 & $<1.1$ & $<0.9$ & $<0.9$ & 1.3 & $<1.1$ & $<0.9$ & 5.6 & 18.3 & $<1.1$ & $<0.9$ & 17.2 & 50.4 \\
\hline 6 & $<1.1$ & $<0.9$ & $<0.9$ & 1.4 & $<1.1$ & $<0.9$ & 8.3 & 32.4 & $<1.1$ & $<0.9$ & 29.5 & 52.0 \\
\hline 10 & $<1.1$ & $<0.9$ & 1.3 & 4.0 & $<1.1$ & $<0.9$ & 12.3 & 32.9 & $<1.1$ & $<0.9$ & 40.7 & 125.1 \\
\hline 20 & n.d. & $<0.9$ & 2.4 & 4.1 & n.d. & $<0.9$ & 25.7 & 66.3 & n.d. & $<0.9$ & 82.5 & 180.8 \\
\hline 30 & n.d. & $<0.9$ & 3.4 & 5.4 & n.d. & $<0.9$ & 38.7 & 77.2 & n.d. & 1.6 & 121.2 & 258.3 \\
\hline
\end{tabular}

n.d. not determined 
Table 5: Migration kinetics of toluene from spiked PET bottle into soft drinks and juices at $40{ }^{\circ} \mathrm{C}$

\begin{tabular}{|c|c|c|c|c|c|c|c|}
\hline \multirow[b]{3}{*}{$\begin{array}{l}\text { time } \\
\text { [d] }\end{array}$} & \multicolumn{7}{|c|}{ concentration in beverage $[\mu \mathrm{g} / \mathrm{kg}]$} \\
\hline & \multicolumn{7}{|c|}{ Bottle wall concentration: $297.5 \pm 1.2 \mathrm{mg} / \mathrm{kg}$} \\
\hline & $\begin{array}{l}\text { Orange } \\
\text { juice }\end{array}$ & $\begin{array}{l}\text { Apple } \\
\text { juice (cloudy) }\end{array}$ & $\begin{array}{l}\text { Apple } \\
\text { juice (clear) }\end{array}$ & $\begin{array}{l}\text { Vitamins ACE } \\
\text { juice }\end{array}$ & $\begin{array}{l}\text { Flavoured water } \\
\text { (apple kiwi) }\end{array}$ & $\begin{array}{l}\text { Flavoured water } \\
\text { (peach tea) }\end{array}$ & $\begin{array}{l}\text { Soft drink } \\
\text { (cola) }\end{array}$ \\
\hline 3 & 10.0 & 6.3 & 3.4 & 26.1 & 15.5 & 14.6 & 5.7 \\
\hline 6 & 18.9 & 13.0 & 10.7 & 44.5 & 30.2 & 27.3 & 9.2 \\
\hline 10 & 38.4 & 24.6 & 18.6 & 63.4 & 49.4 & 41.1 & 10.8 \\
\hline 20 & 75.7 & 32.8 & 16.7 & 116.6 & 80.9 & 80.9 & 37.6 \\
\hline 30 & 109.0 & 26.8 & 32.5 & 146.7 & 116.9 & 120.3 & 48.4 \\
\hline
\end{tabular}


Table 6: Migration kinetics of chlorobenzene from spiked PET bottle into soft drinks and juices at $40{ }^{\circ} \mathrm{C}$

\begin{tabular}{|l|l|l|l|l|l|l|l|}
\hline \multicolumn{6}{|l|}{ concentration in beverage [ $[\mathrm{gg} / \mathrm{kg}]$} \\
\hline \multirow{2}{*}{$\begin{array}{l}\text { time } \\
\text { [d] }\end{array}$} & $\begin{array}{l}\text { Orttle wall concentration: } 357.8 \pm 1.5 \mathrm{mg} / \mathrm{kg} \\
\text { juice }\end{array}$ & $\begin{array}{l}\text { Apple } \\
\text { juice (cloudy) }\end{array}$ & $\begin{array}{l}\text { Apple } \\
\text { juice (clear) }\end{array}$ & $\begin{array}{l}\text { Vitamins ACE } \\
\text { juice }\end{array}$ & $\begin{array}{l}\text { Flavoured water } \\
\text { (apple kiwi) }\end{array}$ & $\begin{array}{l}\text { Flavoured water } \\
\text { (peach tea) }\end{array}$ & $\begin{array}{l}\text { Soft drink } \\
\text { (cola) }\end{array}$ \\
\hline 3 & 9.8 & 10.2 & 5.1 & 21.8 & 22.3 & 22.0 & 12.8 \\
6 & 20.2 & 20.0 & 15.8 & 40.7 & 43.2 & 40.8 & 22.2 \\
10 & 44.9 & 36.5 & 30.3 & 62.7 & 70.6 & 60.6 & 32.5 \\
20 & 99.5 & 56.2 & 31.3 & 124.9 & 116.1 & 117.2 & 72.7 \\
30 & 141.2 & 56.5 & 57.0 & 183.0 & 141.5 & 162.4 & 95.8 \\
\hline
\end{tabular}




\section{Equation 1:}

$$
\frac{m_{t}}{A}=\frac{2}{\sqrt{\pi}} c_{P, 0} \sqrt{D_{P} t}
$$

Equation 2:

$$
D_{P}=10^{4} \exp \left[A_{P}-0.1351 M_{r}^{2 / 3}+0.003 M_{r}-\frac{R \cdot 10454}{R \cdot T}\right] \quad\left[\mathrm{cm}^{2} / \mathrm{s}\right]
$$

where: $A_{P}=A_{P}^{\prime}-\frac{\tau}{T}$

$$
\begin{aligned}
& \text { with : } \quad M_{r}: \quad \text { relative molecular mass of migrant [Dalton] } \\
& \text { T: } \quad \text { temperature }[\mathrm{K}]
\end{aligned}
$$

$A_{p}^{\prime}: \quad$ an upper limit polymer specific diffusion parameter

$\tau$ : $\quad$ a polymer specific "activation energy" parameter $[\mathrm{K}]$

$R: \quad$ gas constant $\left[8.3145 \mathrm{~J} \mathrm{~mol}^{-1} \mathrm{~K}^{-1}\right]$

$R$ 10454: reference activation energy $\mathrm{E}_{\mathrm{A}, \text { ref }}[\mathrm{K}]$ for the diffusion in polymer 


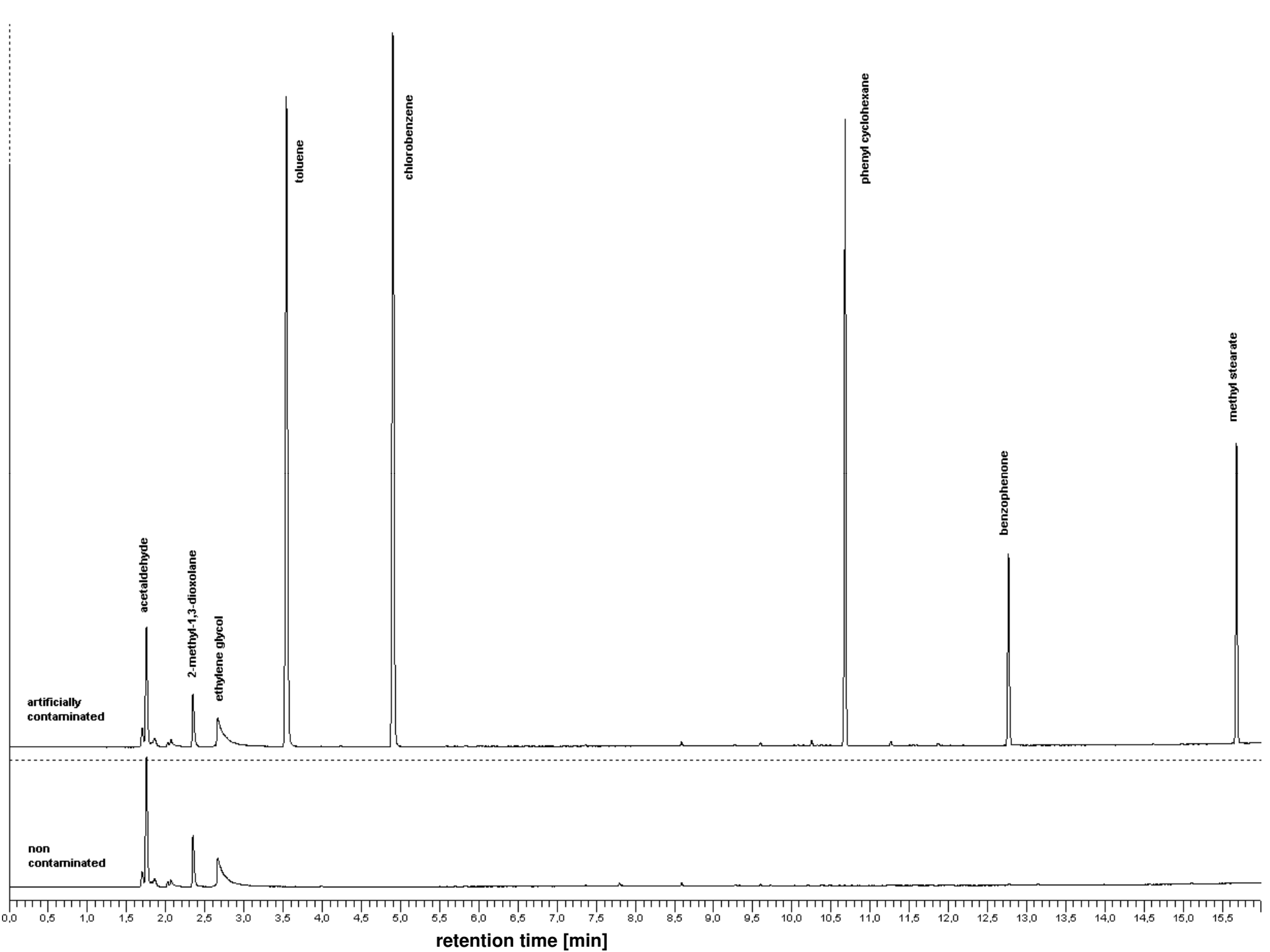

Figure 1: Headspace gas chromatogram of a reference PET bottle (without artificial contamination) and a PET bottle spiked at the lowest contamination level 


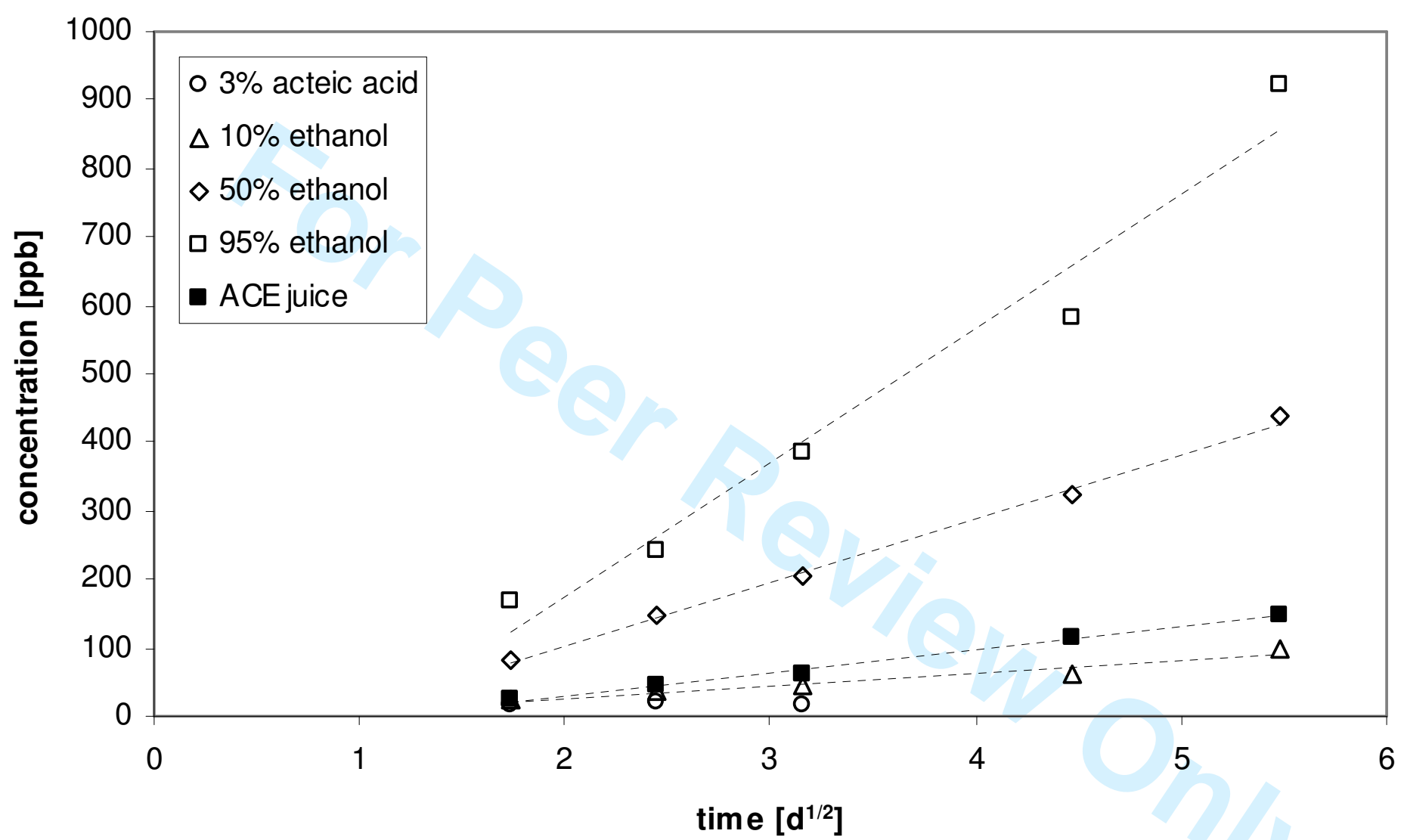

Figure 2: Migration kinetics of toluene from spiked PET bottle (initial toluene concentration $298 \mathrm{mg} / \mathrm{kg}$ ) into food simulants and the vitamin ACE juice at $40{ }^{\circ} \mathrm{C}$ 


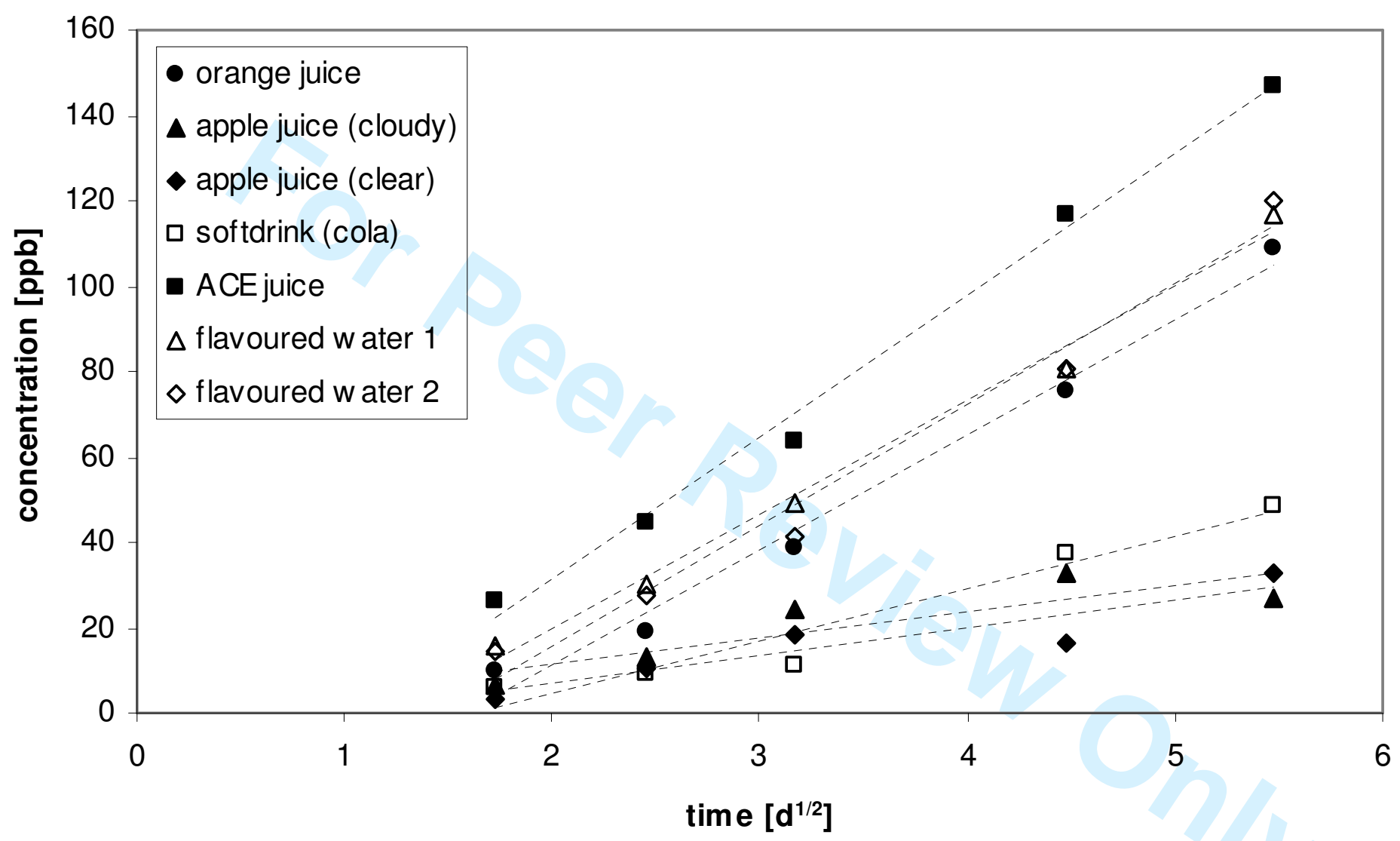

Figure 3: Migration kinetics of toluene from spiked PET bottle (initial toluene concentration $298 \mathrm{mg} / \mathrm{kg}$ ) into various beverages at $40{ }^{\circ} \mathrm{C}$ 


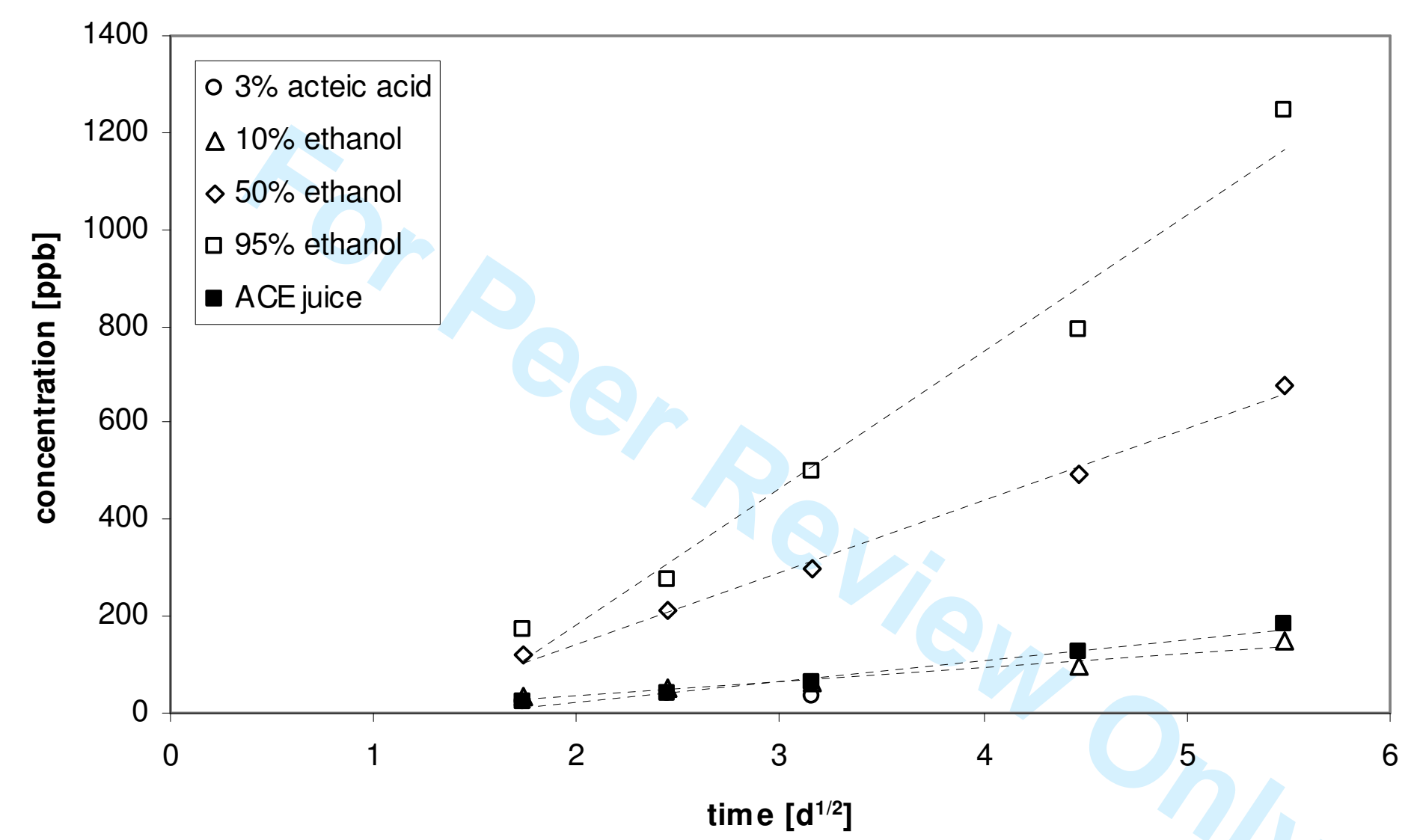

Figure 4: Migration kinetics of chlorobenzene from spiked PET bottle (initial chlorobenzene concentration $358 \mathrm{mg} / \mathrm{kg}$ ) into food simulants and the vitamin ACE juice at $40{ }^{\circ} \mathrm{C}$ 


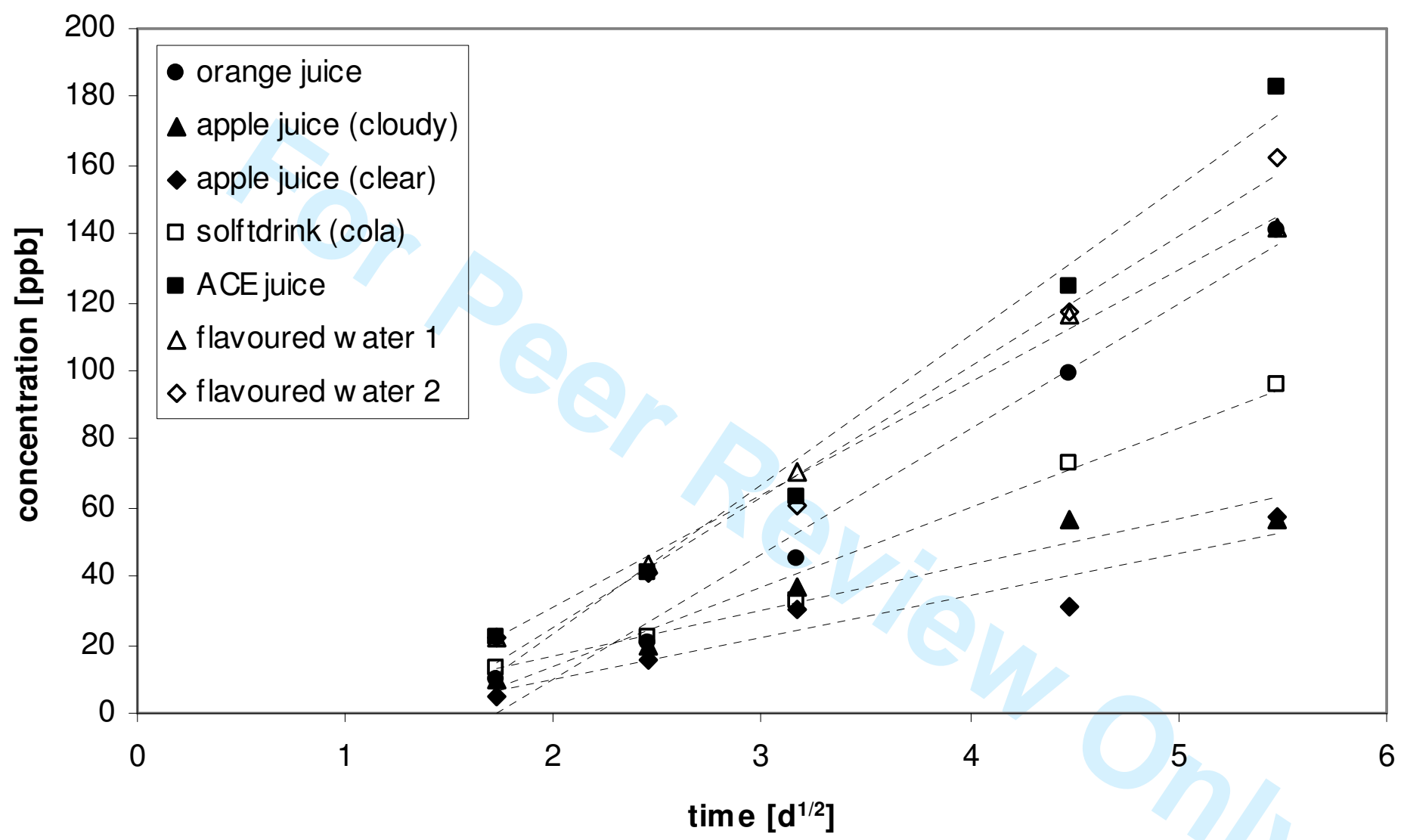

Figure 5: Migration kinetics of chlorobenzene from spiked PET bottle (initial chlorobenzene concentration $358 \mathrm{mg} / \mathrm{kg}$ ) into various beverages at $40^{\circ} \mathrm{C}$ 


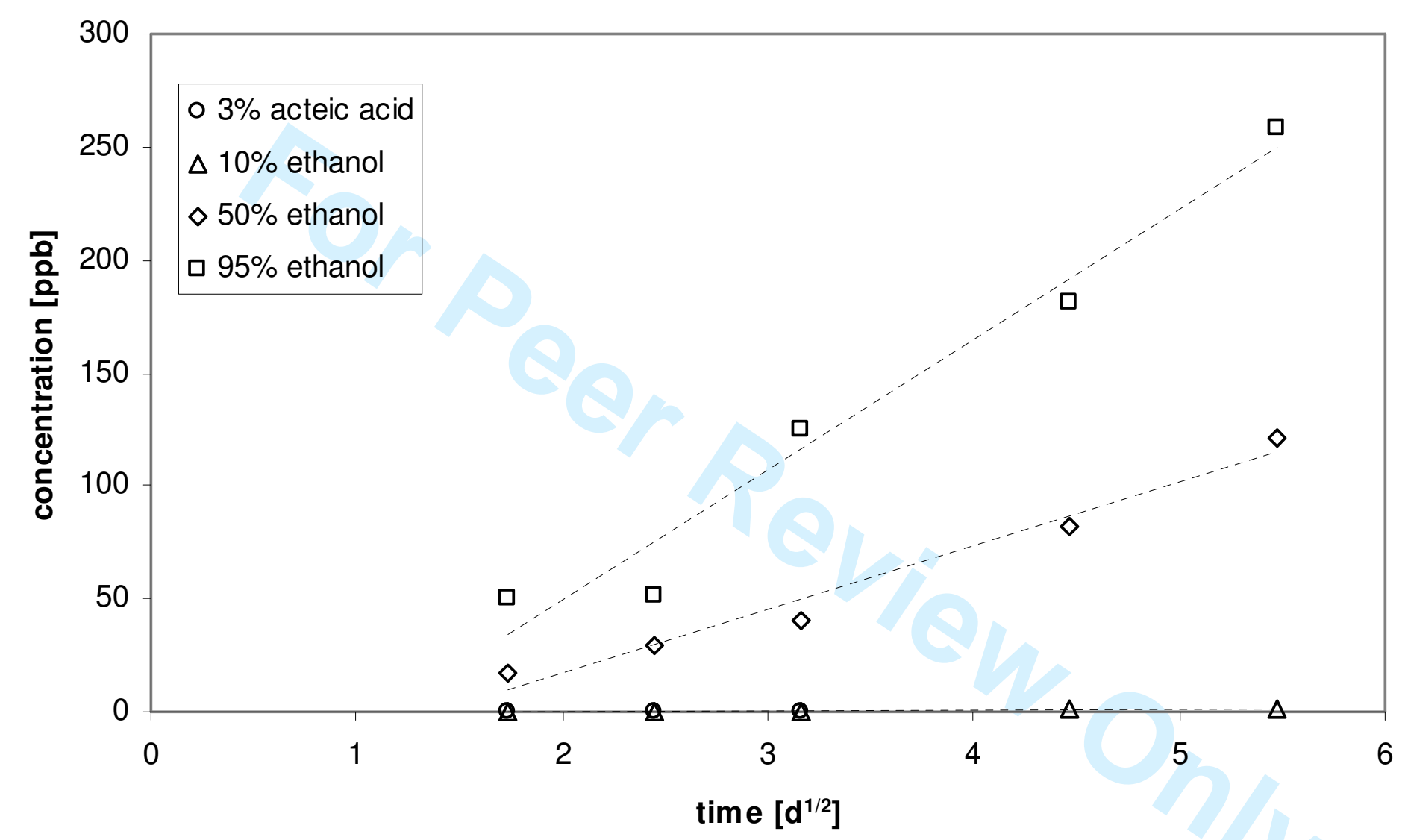

Figure 6: Migration kinetics of phenyl cyclohexane from spiked PET bottle (initial phenyl cyclohexane concentration $782 \mathrm{mg} / \mathrm{kg}$ ) into food simulants at $40{ }^{\circ} \mathrm{C}$ 


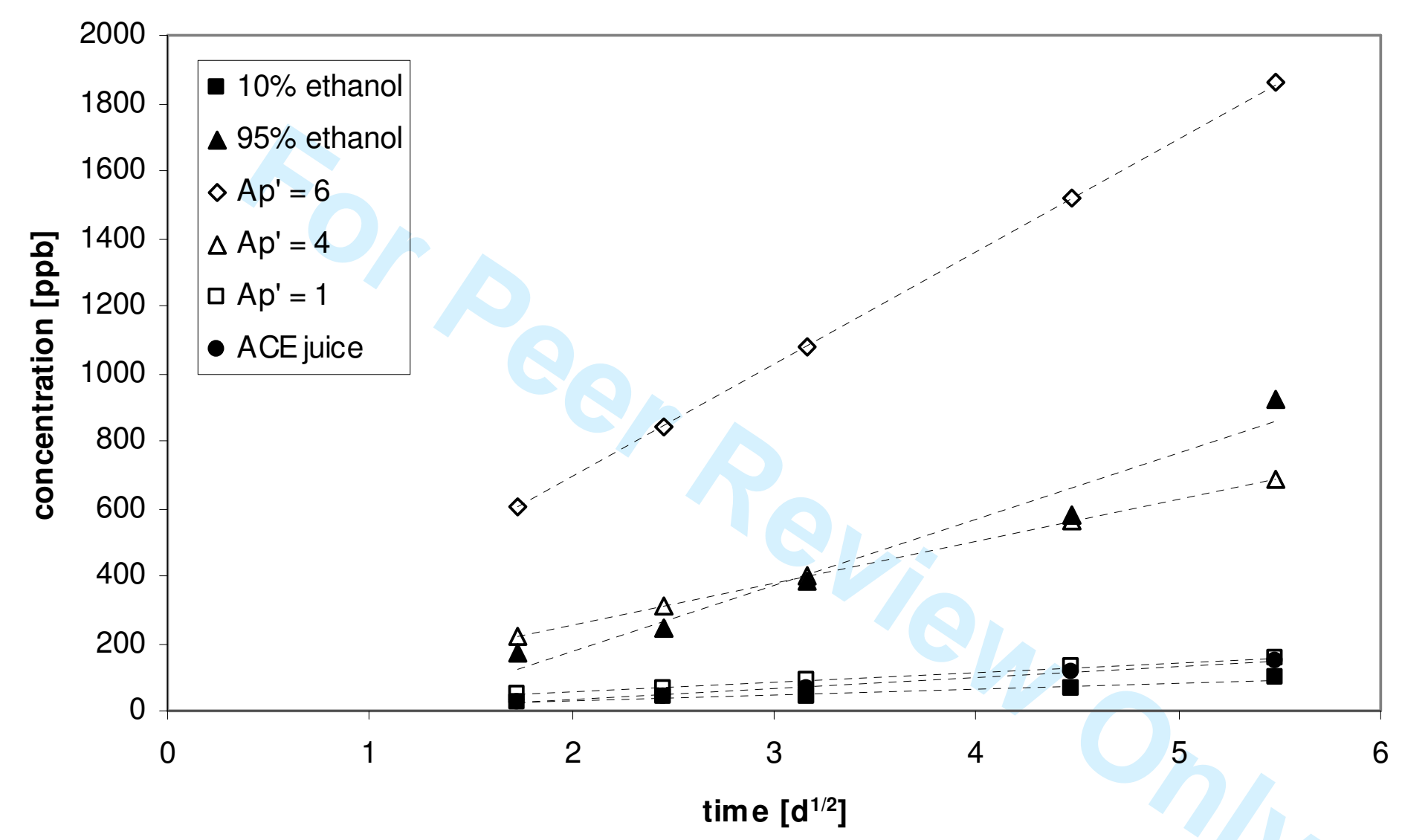

Figure 7: Migration modelling versus experimental migration of toluene (initial concentration in bottle wall: $298 \mathrm{mg} / \mathrm{kg}$ ) at $40{ }^{\circ} \mathrm{C}$ 


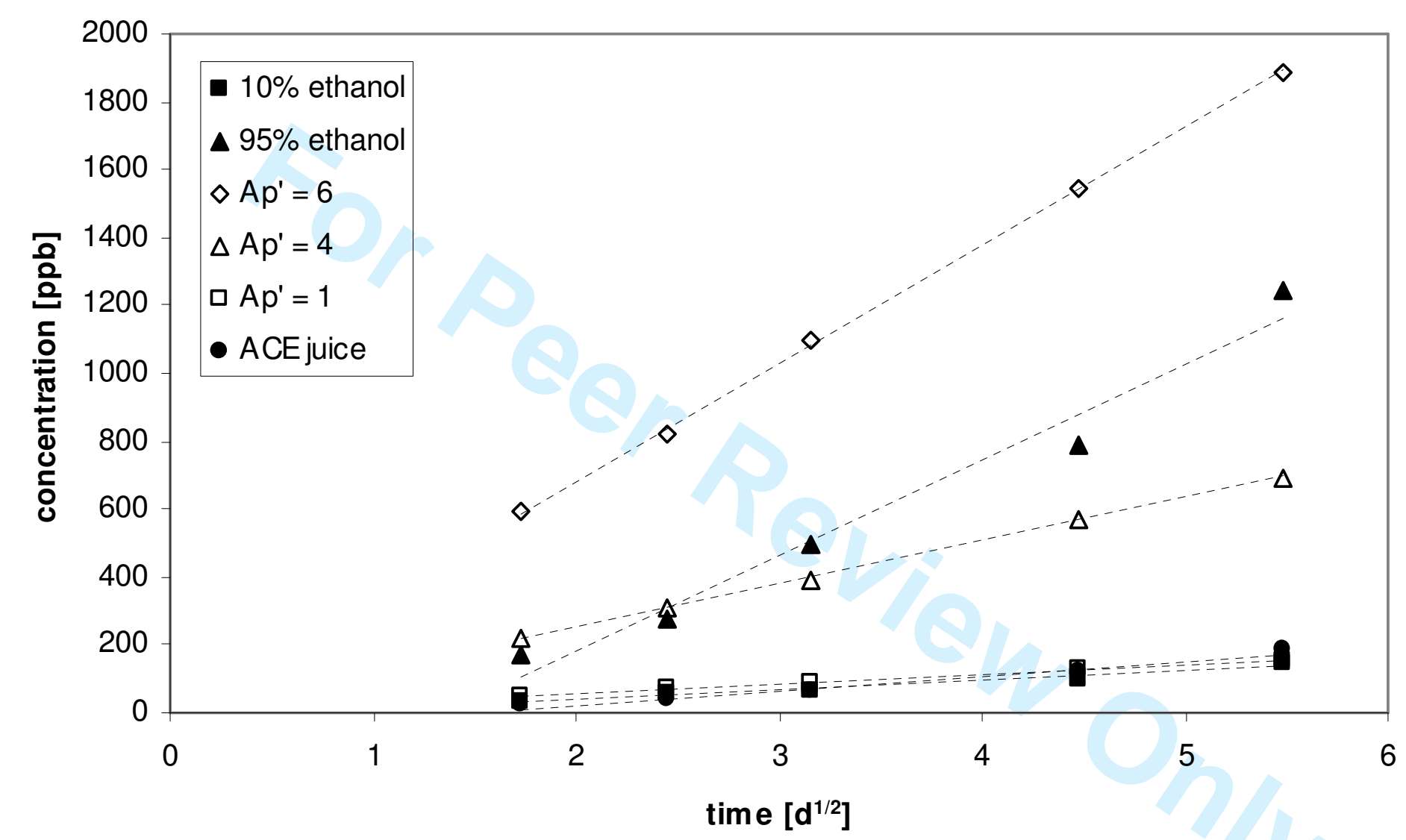

Figure 8: Migration modelling versus experimental migration of chlorobenzene (initial concentration in bottle: $358 \mathrm{mg} / \mathrm{kg}$ ) at $40{ }^{\circ} \mathrm{C}$ 


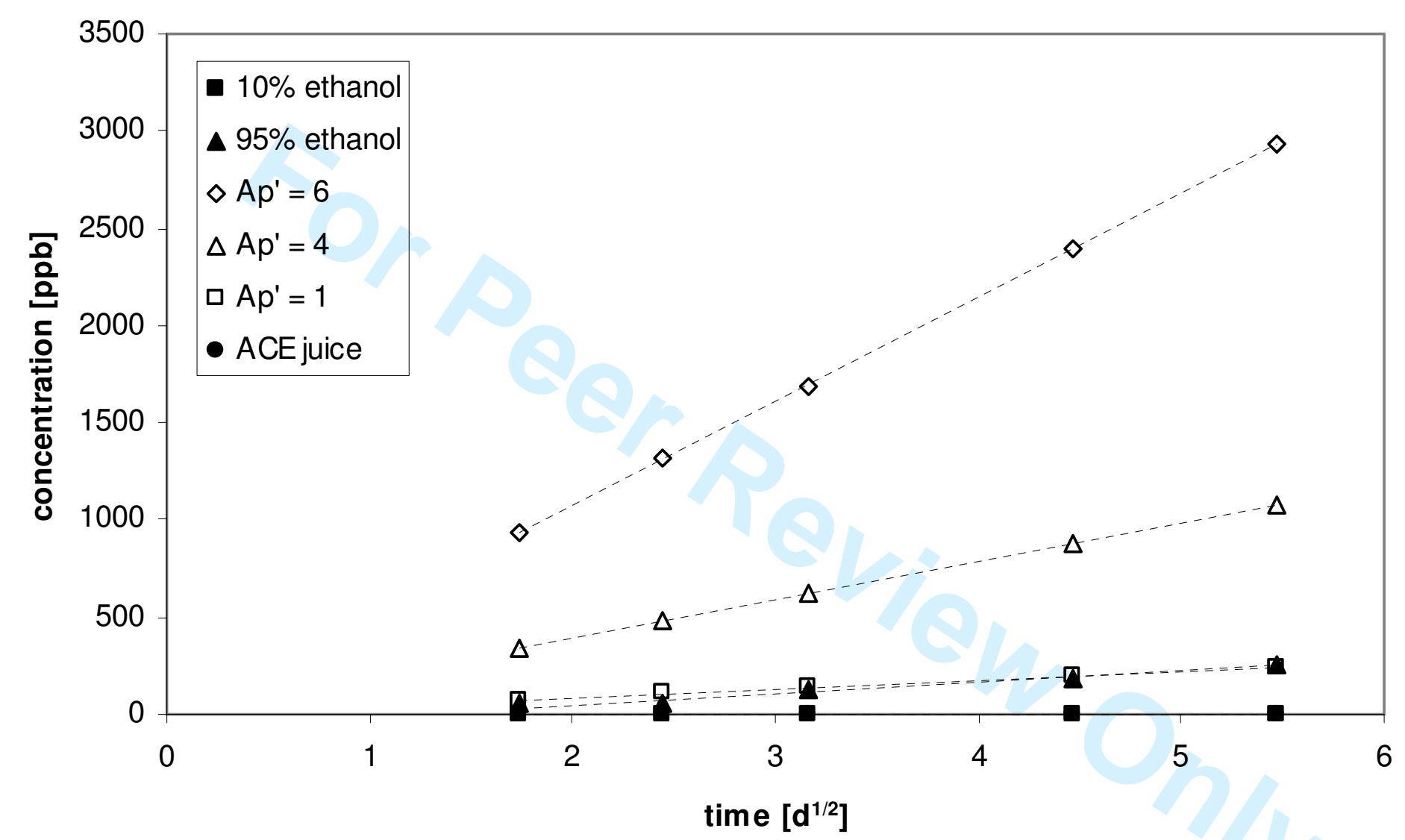

Figure 9: Migration modelling versus experimental migration of phenyl cyclohexane (initial concentration in bottle: $782 \mathrm{mg} / \mathrm{kg}$ ) at $40{ }^{\circ} \mathrm{C}$ 


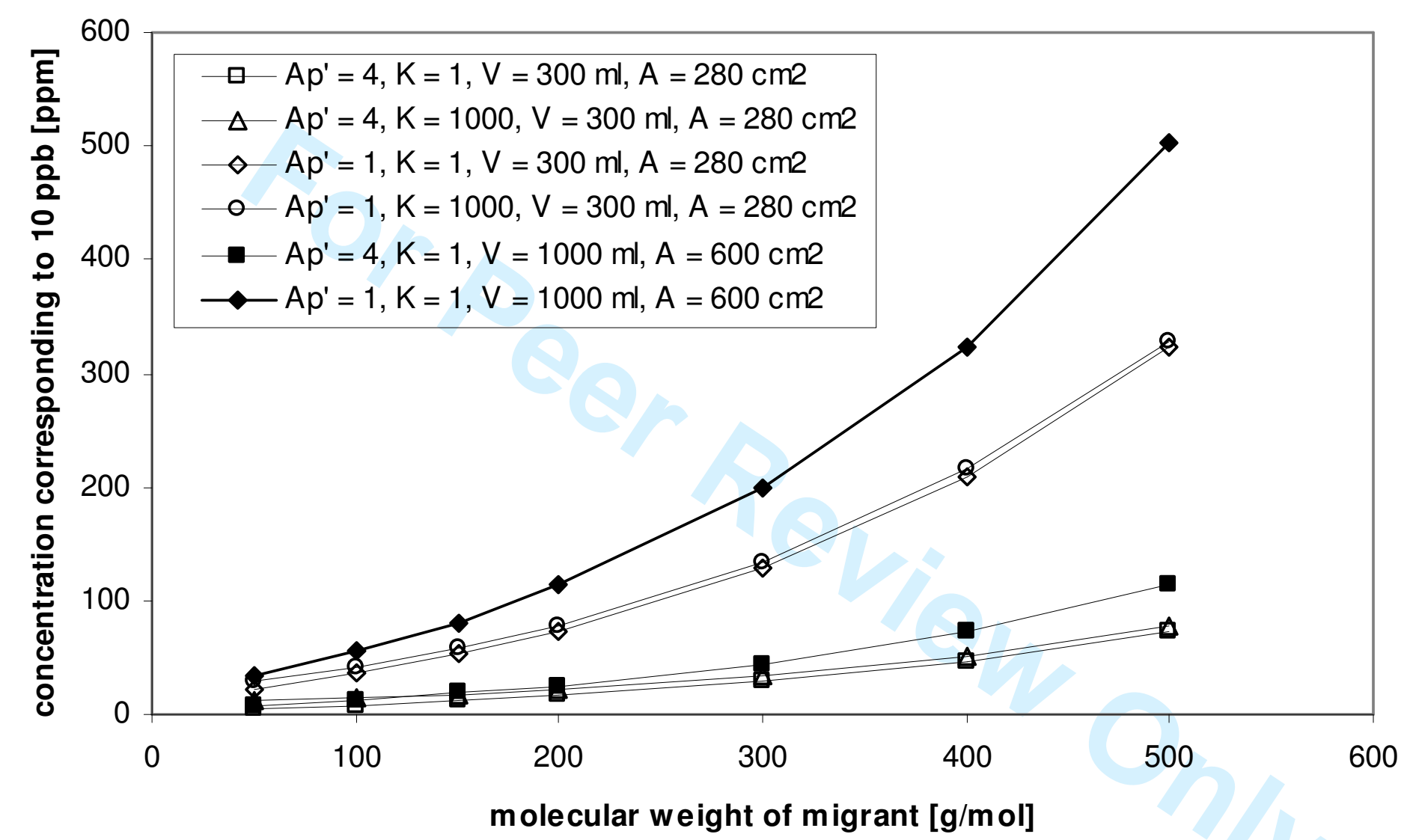

Figure 10: Maximum bottle wall concentrations for substances which corresponds to a migration limit of $10 \mu \mathrm{g} / \mathrm{kg}$ (storage time $10 \mathrm{~d}$, temperature $40^{\circ} \mathrm{C}$ ) 


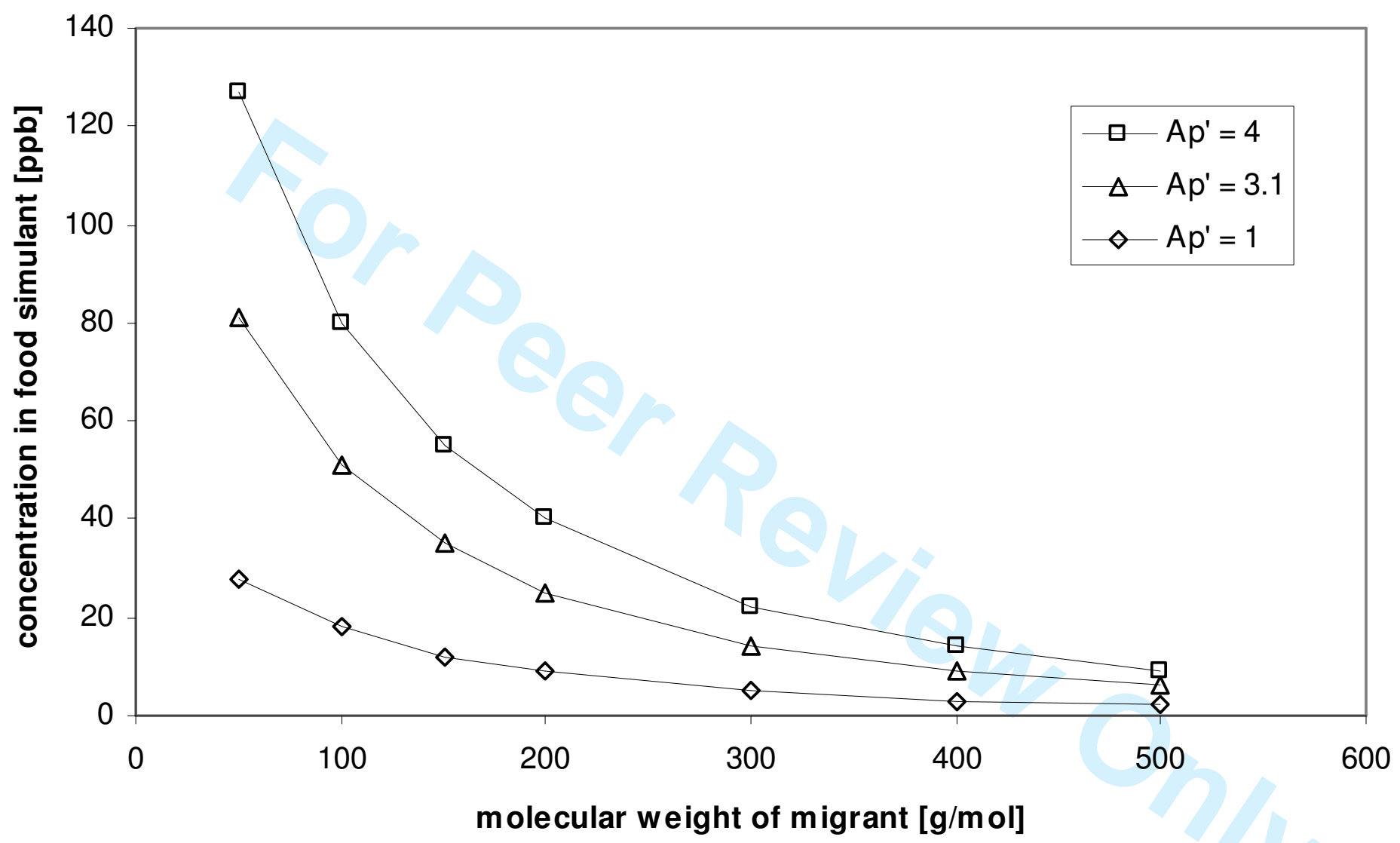

Figure 11: Calculated migration for $10 \mathrm{~d}$ at $40{ }^{\circ} \mathrm{C}$ at a bottle wall concentration $\left(\mathrm{C}_{\mathrm{P}, 0}\right)$ of 100 ppm for the "EU cube" $\left(600 \mathrm{~cm}^{2}, 1000 \mathrm{ml}\right)$ and $A_{P}^{\prime}=4, A_{P}^{\prime}=3.1$ and $A_{P^{\prime}}=1(\mathrm{~K}=1, \tau=1577 \mathrm{~K})$ 